\title{
A conservation plan for a global biodiversity hotspot- the Cape Floristic Region, South Africa
}

\author{
R.M. Cowling ${ }^{\mathrm{a}, *}$, R.L. Pressey ${ }^{\mathrm{b}}$, M. Rouget ${ }^{\mathrm{c}}$, A.T. Lombard ${ }^{\mathrm{a}}$ \\ ${ }^{a}$ Terrestrial Ecology Research Unit and Southern African Hotspots Program: Conservation International, Department of Botany, \\ University of Port Elizabeth, PO Box 1600, Port Elizabeth 6000, South Africa \\ ${ }^{\mathrm{b}}$ New South Wales National Parks and Wildife Service, PO Box 402, Armidale, NSW 2350 Australia \\ ${ }^{\mathrm{c}}$ Institute for Plant Conservation, Department of Botany, University of Cape Town, Private Bag, Rondebosch 7701, South Africa
}

Received 11 November 2002; received in revised form 17 December 2002; accepted 19 December 2002

\begin{abstract}
We produced a conservation plan that achieved conservation targets for biodiversity pattern and process in the species- and endemic-rich Cape Floristic Region of South Africa. Features given quantitative conservation targets were land classes, localities of Proteaceae and selected vertebrate (freshwater fish, amphibians and reptiles) species, population sizes for medium- and large-sized mammals, and six types of spatial surrogates for ecological and evolutionary processes. The plan was developed in several stages using C-Plan, a decision support system linked to a geographic information system. Accepting the existing reserve system as part of the plan, we first selected spatially fixed surrogates for biodiversity processes; then we included those planning units that were essential for achieving targets for land classes, Proteaceae and vertebrate species; next we included areas required to accommodate population and design targets for large and medium-sized mammals; we then selected planning units required to conserve entire upland-lowland and macroclimatic gradients; and finally we resolved the options for achieving remaining targets while also consolidating the design of conservation areas. The result was a system of conservation areas, requiring, in addition to the existing reserve system, $52 \%$ of the remaining extant habitat in the planning domain, as well as restorable habitat, that will promote the persistence and continued diversification of much of the region's biota in the face of ongoing habitat loss and climate change. After describing the planning process, we discuss implementation priorities in relation to conservation value and vulnerability to habitat loss, as well as socio-economic, political and institutional constraints and opportunities.
\end{abstract}

(C) 2003 Elsevier Science Ltd. All rights reserved.

Keywords: Biodiversity persistence; Conservation targets; Ecological and evolutionary processes; Implementation; Restoration; Systematic conservation planning

\section{Introduction}

A great deal of progress has been made in developing and refining techniques to identify representative systems of conservation areas- comprising both formal reserves and a variety of complementary off-reserve management approaches (Pressey et al., 1993; Margules and Pressey, 2000; Possingham et al., 2000; Pressey and Cowling, 2001). However, in addition to representing biodiversity, a goal of establishing conservation areas should be the persistence of the species and processes they contain. This is achieved by excluding processes that threaten biodiversity (Faith and Walker, 1996;

\footnotetext{
* Corresponding author. Tel./fax: + 27-42-2980259.

E-mail address: rmc@kingsley.co.za (R.M. Cowling).
}

Pressey et al., 1996) and by designing systems that support the population, ecological and evolutionary processes that maintain and generate biodiversity (Smith et al., 1993; Balmford et al., 1998; Margules and Pressey, 2000).

In addition to spatial considerations, achieving persistence requires the consideration of time over a wide range of scales. Surprisingly little attention has been given to many temporal phenomena in conservation planning. Perhaps the best developed aspect of temporal issues in planning has been the research and applications on population dynamics and persistence (Soulé and Terborgh, 1999; Hanski and Ovaskainen, 2000; Reed et al., 2002). Other important processes have received much less attention. While some studies have identified and targeted for conservation the spatial surrogates for processes that 
operate over ecological (e.g. Baker, 1989) and evolutionary (e.g. Fjeldså and Rahbek, 1998; Moritz and Faith, 1998) time scales, only Cowling et al. (1999a) have attempted this for a wide array of processes and their associated temporal scales within an entire ecoregion. Time is also a key factor in implementing conservation action. Pressey et al. (1996) identified the vulnerability of areas to processes that threaten biodiversity as a key determinant (along with conservation value) for scheduling conservation action; conservationworthy sites that are vulnerable in the short-term are priorities for immediate action (see also Pressey and Taffs, 2001).

Conservation planners in North America (Dinerstein et al., 2000; Groves et al., 2000) and in the southern hemisphere (Margules and Pressey, 2000; Pressey and Cowling, 2001) have now identified planning protocols that seek to achieve targets for both pattern (species, habitats) and process. The sequences of planning decisions and their specific considerations have tended to differ between these two "schools" of thinking, but there is increasing convergence between them as each incorporates ideas from the other while also making new contributions (Margules and Pressey, 2000; Groves et al., 2002; Noss et al., 2002). In this paper we describe the approach, and discuss the outcomes of a systematic conservation plan for a biodiversity hotspot, the Cape Floristic Region (CFR). The plan aimed to achieve explicit conservation targets for biodiversity pattern and process. Features targeted were land classes, localities of Proteaceae and selected vertebrate (freshwater fish, amphibians and reptiles) species, population sizes for large and medium-sized mammals, and six types of spatial surrogates for ecological and evolutionary processes. To our knowledge, this is the first conservation planning study that has strived to achieve simultaneously targets for such a wide array of biodiversity features.

We stress that this is a "real world" study, aimed at providing spatially explicit guidelines for implementation (Gelderblom et al., 2003). The initial planning for this study (Cowling et al., 1999b) formed part of the Cape Action Plan for the Environment (CAPE), a 2-year project, started in late 1998, that was funded by the Global Environment Facility and designed to develop a strategy and action plan for the conservation of the CFR's embattled biodiversity (Younge and Ashwell, 2000; Younge and Fowkes, 2003). The goal of CAPE (Lochner et al., 2003) is as follows:

By the year 2020, the natural environment and biodiversity of the fynbos region will be effectively conserved, restored wherever appropriate, and will deliver significant benefits to the people of the region in a way that is embraced by local communities, endorsed by government and recognised internationally.
The 20-year implementation programme is now known as Cape Action for People and the Environment (CAPE) (www.capeaction.org.za). Many of the component projects, which are funded by both local and international agencies, are concerned with the root causes of threats to the region's biodiversity, especially lack of capacity and poor co-ordination between agencies responsible for management of natural resources, and lack of awareness of the importance of biodiversity for local and regional economies (Gelderblom et al., in press). The plan we describe here is being used in projects aimed at guiding land use plans prepared by provincial planning agencies and municipal officials (Gelderblom et al., 2002), establishing reserves in priority parts of the region (e.g. Boshoff et al., 2000), and introducing new off-reserve conservation mechanisms (e.g. Privett et al., 2002).

Finally, we must stress that our plan is only one of many options for achieving the conservation targets that we have formulated to make operational the broad goal for the future of the region's biodiversity (Lochner et al., 2003). During the 20-year implementation period, many opportunities and constraints for action will emerge: additional reserves will be established and habitat in priority areas will be lost before effective conservation action can be put in place. The data layers will be updated, the targets modified and new priorities will emerge. What we describe here is the first phase of a protracted planning process.

\section{Study area}

The planning domain for this study is centred on the Cape Floristic Region (CFR), as delimited by Cowling and Heijnis (2001), an area of $87,892 \mathrm{~km}^{2}$. The domain encompasses an extension of approximately $60 \mathrm{~km}$ beyond the boundaries of the CFR. This was done to allow the conservation plan to link the CFR with adjacent regions (Namaqualand, Tanqua Karoo, Great Karoo etc). The area of the planning domain is 122,590 $\mathrm{km}^{2}$ (Fig. 1).

The CFR has long been recognised as a global priority for conservation action. Owing to its high concentration of endemic taxa, especially of plants $(70 \%$ of the region's 9000 species are endemic-Goldblatt and Manning, 2002), and its vulnerability to processes that threaten this unique biodiversity, the CFR has been identified as a biodiversity hotspot of global significance (Mittermeier et al., 1998; Myers et al., 2000). Globally, the region is also listed as a Centre of Plant Diversity (Davis et al., 1994), an Endemic Bird Area (Stattersfield et al., 1998) and a Global 200 Ecoregion (Olson and Dinerstein, 1998). It is also a centre of diversity and endemism for mammals (Brooks et al., 2001; Kerley et al., 2003), other vertebrates (freshwater fish, amphibia 
and reptiles) (Branch, 1988; Skelton et al., 1995; Impson et al., 1999; Brooks et al., 2001), and many invertebrate groups (Stuckenberg, 1962; Picker and Samways, 1996). The region is home to 1406 Red Data Book plant species, one of the highest known concentrations of such species in the world (Cowling and Hilton-Taylor, 1994). The hallmark feature of the CFR's biodiversity is the exceptionally high diversity and endemism of vascular plants and invertebrates.

Approximately $30 \%$ of the CFR is currently transformed by cultivated land (including forestry plantations) $(25.9 \%$ of the region), urban areas $(1.6 \%)$, and dense stands of invasive alien trees $(1.6 \%)$ (Rouget et al., 2003a). The total area of untransformed land in the planning domain is $95,579 \mathrm{~km}^{2}$, or $78 \%$ of its area. Some $19,350 \mathrm{~km}^{2}$ or $22 \%$ of the CFR is included in either statutory reserves $(49 \%$ of the conservation estate comprising 132 individual reserves) or non-statutory reserves (51\% in 213 reserves) (Rouget et al., 2003b). Statutory reserves are supported by strong legal and institutional structures and controlled at the national and provincial level. Non-statutory reserves have a lower level of legal and institutional support (Rouget et al., 2003b). Reserves are biased towards upland areas and this has seriously constrained representation of biodiversity pattern and processes (Rouget et al., 2003b).

\section{Methods}

\subsection{Expert involvement in data and planning decisions}

We used a planning approach that integrated data and software with expert judgements. Expert knowledge was used in compiling most of the data sets, namely the land classes or broad habitat units (Cowling and Heijnis, 2001; see Section 3.2.1), the densities and spatial requirements of large and medium-sized mammals (Kerley et al., 2003), and the spatial surrogates for ecological and evolutionary processes (hereafter "spatial components"-Rouget et al., in press). Expert judgement was also used in developing the plan, namely in designing areas for achieving targets for large and medium-sized mammals (Kerley et al., 2003; see Sections 3.2.3 and 3.6.4), identifying the most suitable locations for upland-lowland and macroclimatic gradients (Table 1; see Sections 3.6.5 and 3.6.6) and, at the final stage of plan development, in selecting areas that achieved all outstanding targets (see Section 3.6.7).

\subsection{Biodiversity features}

We targeted five different biodiversity features for the plan. These are land classes, locality records for Proteaceae and selected vertebrates, large and medium-sized mammals, and ecological and evolutionary processes. Features comprising components entirely or largely restricted to the CFR are land classes, these being surrogates for plants and much undescribed and undocumented biodiversity which is likely to be endemic; Proteaceae ( $97 \%$ endemic); and the processes. The vertebrate assemblage is of moderate to low endemism (46\% for amphibians, $16 \%$ for reptiles, and $13 \%$ for freshwater fish), while only three of the 41 species of large and medium-sized mammals are endemic to the CFR.

\subsubsection{Land classes}

We used land classes termed broad habitat units (BHUs) that are surrogates for overall biodiversity in the CFR (Boshoff et al., 2001; Cowling and Heijnis, 2001; Lombard et al., 2003). These were derived by intersecting layers of vegetation, homogeneous climate zones (Dent et al., 1990), geology and topography in a geographic information system (GIS), and then using expert knowledge to refine boundaries (Cowling and Heijnis, 2001). A total of 16 primary and 102 secondary BHUs occur in the planning domain, the latter ranging in size from 18 to $6194 \mathrm{~km}^{2}$ (with an average of 1202 $\mathrm{km}^{2}$ ). Subsequent text on BHUs refers to secondary BHUs.

\subsubsection{Locality records for Proteaceae and vertebrates}

The species locality distributions comprised two data sets, one for Proteaceae (364 taxa, 183,181 records), and the other for selected vertebrates (freshwater fish, amphibians and reptiles; 345 taxa, 8472 records). All data sets include only indigenous taxa, classified to sub-species where possible. All references to species in this study should thus be read as species or subspecies. The Proteaceae data were obtained from the Protea Atlas Project (National Botanical Institute, http://protea.worldonline.co.za). This is the most complete plant distribution data set in South Africa. Hereafter, the Proteaceae (comprising 13 genera) are referred to as proteas. The vertebrate data were obtained from Scientific Services Division, Western Cape Nature Conservation Board, and museum records (see Lombard et al., 2003). These data are less complete than the protea data, but contain the only readily available digital point locality data for these groups in the planning domain. Both data sets contain presence-only, rather than presence-absence, data. Furthermore, unlike the large and medium-sized mammals (see Section 3.2.3), we lacked information on the wider distributions and habitat associations of the members of these two taxon groups.

For the protea data set, we filtered out locality pseudoreplicates arising from the strategy of temporal resampling. Pressey et al. (2003) describe how this was done. This reduced the number of protea records by $3.9 \%$ to 176,082 . Owing to the wide dispersion of 
Table 1

Characteristics of the spatial components of ecological and evolutionary processes in the Cape Floristic Region

\begin{tabular}{|c|c|c|c|c|}
\hline Spatial component & Process $^{\mathrm{a}}$ & Method of definition ${ }^{\mathrm{b}}$ & $\begin{array}{l}\text { No. sub- } \\
\text { components }^{c}\end{array}$ & $\begin{array}{l}\text { Lost }^{\mathrm{d}} \\
(\%)\end{array}$ \\
\hline Edaphic interfaces & Ecological diversification of plant lineages & $\begin{array}{l}500 \mathrm{~m} \text { buffer along juxtaposed } \mathrm{BHUs}^{\mathrm{e}} \text { on acid and alkaline substrata (comprising } \\
\text { a 1-km-wide strip) }\end{array}$ & 8 & 8.7 \\
\hline Upland-lowland interfaces & Ecological diversification of plant lineages & $500 \mathrm{~m}$ buffer between all lowland and upland BHUs (comprising a 1-km-wide strip) & 146 & 2.4 \\
\hline Entire sand movement corridors & $\begin{array}{l}\text { Inland movement of marine sands and } \\
\text { associated soil development }\end{array}$ & Functional corridor comprising intact source and sink areas & 7 & 5.1 \\
\hline Whole inter-basin riverine corridors & $\begin{array}{l}\text { Migration and exchange between inland } \\
\text { and coastal biotas }\end{array}$ & $\begin{array}{l}250 \mathrm{~m} \text { buffer along riverine systems linking coastal and inland subregions (comprising } \\
\text { a } 500 \text {-m-wide strip) }\end{array}$ & 6 & 1.7 \\
\hline Upland-lowland gradients & $\begin{array}{l}\text { Ecological diversification of plant and } \\
\text { animal lineages; migration of biota }\end{array}$ & $\begin{array}{l}\text { 1-km-wide paths of untransformed habitat linking unique combinations of lowland } \\
\text { and upland BHUs. The paths were used as guides for identifying gradients comprising } \\
\text { sixteenth-degree planning units during development of the plan }\end{array}$ & 85 & 0 \\
\hline Macroclimatic gradients & $\begin{array}{l}\text { Geographic diversification of plant and } \\
\text { animal lineages; migration of biota }\end{array}$ & $\begin{array}{l}\text { 1-km-wide paths of untransformed habitat linking major biogeographic zones. The } \\
\text { paths were used as guides for identifying gradients comprising sixteenth-degree } \\
\text { planning units during development of the plan }\end{array}$ & 3 & 0 \\
\hline
\end{tabular}

Details on the methods of identification are given in Rouget et al. (in press).

${ }^{\mathrm{c}}$ Subcomponents comprise sections of components, namely a particular interface between two edaphically contrasting BHUs; a unique interface between adjacent upland and lowland BHUs, an individual sand movement or riverine corridor (see Rouget et al., in press, for details).

d Transformed by urbanization.

e $\mathrm{BHU}=$ broad habitat unit (Cowling and Heijnis, 2001). 
vertebrate records, no filtering was done on this data set. Hereafter, we refer to the species records of both taxon groups as populations.

\subsubsection{Large and medium-sized mammals}

This data set provided information on the distributions and densities of 41 species of large and mediumsized mammals, i.e. mammals with body weights larger than about $2 \mathrm{~kg}$ that occur, or previously occurred, naturally in the CFR (Boshoff et al., 2001). While recognizing that options for conserving viable populations of most of these species might be more easily achieved outside of the CFR (Rebelo, 1992), we decided to target this assemblage for three reasons (see Kerley et al., 2003): (i) to represent viable populations of the three endemic taxa, together with other members of this assemblage with which they interact; (ii) to ensure that process associated with this assemblage (e.g. herbivory, dispersal, predation) are incorporated wherever feasible into the plan; and (iii) as focal species (Noss et al., 2002), to provide spatially explicit information about the size, configuration and connectivity requirements for the plan that would otherwise be overlooked.

The data set was prepared to ensure that adequate population sizes of these species were included in the regional conservation plan, and that the configuration of the plan was influenced by the spatial requirements of the larger species. Boshoff and Kerley (2001) estimated species' distributions within the region in relation to BHUs, distinguishing between core habitat (BHUs with the potential to sustain significant breeding populations), marginal habitat (BHUs that could support small populations in scattered suitable habitat or that could be used occasionally), and unsuitable habitat (BHUs where species were unlikely to occur). Boshoff et al. $(2001,2002)$ extended this work by estimating potential densities of individuals in each BHU, excluding two species-hippopotamus and Cape clawless otter - that are associated with unmapped riparian and aquatic habitats. For herbivores, they estimated densities conservatively from information that included type of forage required (feeding guild), agricultural stocking rates, and sharing of available forage between co-occurring species in the same feeding guild. They estimated densities of omnivores and carnivores conservatively from the distributions of prey species, reviews of habitat associations, and estimates (usually the largest) of areal requirements from the literature on the CFR and comparable areas elsewhere.

\subsubsection{Spatial components of processes}

The biodiversity of the CFR is maintained and generated by a wide array of ecological and evolutionary processes operating over spatial scales of a few hectares to hundreds of thousands of hectares (Cowling and Pressey, 2001; Linder, in press). Many of these processes can be accommodated in conservation planning by considering the sizes, rather than specific locations, of new conservation areas, recognising that larger areas, where there are choices, are preferable (Kruger, 1977; Pressey et al., 2003). However, small areas should not be dismissed as a subset of processes can be maintained in them. For example, plant and invertebrate diversity can be maintained in habitat fragments as small as 5 ha provided they are subject to appropriate fire regimes and kept free of invasive plants (Bond et al., 1988; Cowling and Bond, 1991; Kemper et al., 1999; Donaldson et al., 2002). Consequently, populations of specialised pollinators that are responsible for driving speciation in numerous lineages (e.g. Johnson, 1995; Goldblatt and Manning, 1999) can also be maintainedalong with those of their host plants - in very small areas (see Steiner, 1998). At least 1000 plant species in the CFR are naturally rare (Cowling and Lombard, 2002) and many of these have global populations confined to areas of one to a few hectares; the implication is that viable populations can be maintained in very small areas (Cowling and Eggenberg, 2000) and that small areas can play an important role in conserving some processes.

Some processes do not need particular locations or configurations for their maintenance. One example is recurrent fire, which is a key driver of ecological (Bond and van Wilgen, 1996) and evolutionary (Linder, in press) processes in most ecosystems. Similarly, processes associated with herbivory by large and medium-sized mammals do not, for the most part, rely on specific spatial components for their maintenance (Kerley et al., in press). Other processes require particular spatial configurations and specific BHUs or combinations of BHUs. They are therefore likely to be partly or wholly overlooked in a conservation plan unless specifically targeted.

We incorporated in this study the ecological and evolutionary processes that maintain and generate biodiversity over relatively large spatial scales in the region by identifying six spatial components that serve as their surrogates (Cowling and Pressey, 2001; Pressey et al., in press; Rouget et al., 2003b, in press). We define spatial components as the physical features of the CFR with which particular ecological and evolutionary processes are associated. Table 1 provides a summary of the characteristics of these spatial components. Rouget et al. (in press) and Pressey et al. (2003) provide details on their delimitation, configuration and role in conservation.

Four of these components (edaphic interfaces, upland-lowland interfaces, entire sand movement corridors, and whole inter-basin riverine corridors) are spatially fixed, i.e. there are no options for locating them. For the remaining two-upland-lowland gradients and macroclimatic gradients - there is more than one option for their location. For the latter, we identified preliminary paths in ArcInfo (ESRI, Redlands, 
California) (see Rouget et al., in press, for details) as an aid to their delineation in the planning process (see Sections 3.6.5 and 3.6.6).

While Rouget et al. (in press) identified seven macroclimatic gradients (three in the uplands and four in the lowlands) to accommodate ongoing geographic diversification and migration of biota, we excluded the latter from the planning exercise. Our rationale was that there is less evidence for geographic, as opposed to ecological diversification on the lowlands (Linder, in press) and, with the exception of the calcareous sands of the coastal margin, the major climatic gradients on the lowlands are truncated by edaphic discontinuities that are likely to impede adjustment of plant distributions.

We emphasise that, like surrogates for biodiversity pattern (Ferrier, 2002), our spatial surrogates for processes are approximate. At the same time, there is enough information (Cowling and Pressey, 2001; Pressey et al., 2003) to indicate that these spatial components should be important parts of a regional plan. We acknowledge that some of the interfaces and gradients that we have delineated might prove too narrow to promote the diversification and dispersal they are intended to facilitate. But their delineation serves a larger purpose as part of the architecture of the regional plan. Some parts of fixed process components were incorporated into larger conservation areas. Also, the upland-lowland and macroclimatic gradients were generalised to the width of sixteenth-degree planning units $(>6 \mathrm{~km})$ (see Section 3.4) during development of the regional plan.

\subsection{Targets}

Pressey et al. (2003) describe the context, rationale and method for setting targets for each biodiversity feature. Here we provide a brief overview. Table 2 provides a summary of the targets for each feature.

\subsubsection{Broad habitat units}

For each of the 102 BHUs, we assigned a percentage target, applied to the original (pre-European, i.e. ca. 1650 ) extent of native vegetation, which had three components: a baseline target $(10-25 \%)$ that was larger for BHUs with higher biological heterogeneity; a retention target $(0-30 \%)$ that was larger for BHUs with higher levels of threat (across agriculture, alien plants and urbanization) to their remaining native vegetation; and upward adjustment of targets for some BHUs to reduce the risk of target achievement mainly at their interfaces with other BHUs (Pressey et al., 2003) (Table 2). We converted targets to hectares of extant vegetation, and

Table 2

Summary of targets set for biodiversity features in the Cape Floristic Region [see text and Pressey et al. (2003) for details]

\begin{tabular}{|c|c|c|c|c|}
\hline Feature & No. entities & Baseline target & Retention target & $\begin{array}{l}\text { Total target (baseline } \\
+ \text { retention) }\end{array}$ \\
\hline \multicolumn{5}{|l|}{ Land classes } \\
\hline Broad habitat units (BHUs) ${ }^{a}$ & 102 & $10-25 \%{ }^{\mathrm{b}}$ & $0-30 \% 0^{\mathrm{c}}$ & $10-55 \%{ }^{\mathrm{d}}$ \\
\hline \multicolumn{5}{|l|}{ Species } \\
\hline Proteaceae taxa & $\begin{array}{l}364 \text { spp. } \\
176,082 \text { popns }\end{array}$ & $5-10$ popns $^{\mathrm{e}}$ & $0-5$ popns $^{\mathrm{f}}$ & 5-15 popns \\
\hline Non-mammal vertebrates & $\begin{array}{l}345 \text { spp. } \\
8472 \text { popns }\end{array}$ & 1 popn. & $0-1$ popns $^{\mathrm{f}}$ & $1-2$ popns \\
\hline Large and medium-sized mammals & 41 spp. & $0-2000$ individuals $(200 \text { for } 31 \mathrm{spp} .)^{\mathrm{g}}$ & n.a. & $0-2000$ individuals \\
\hline \multicolumn{5}{|l|}{ Processes $^{\mathrm{h}}$} \\
\hline Edaphic interfaces & 8 & $0-120 \mathrm{~km}$ interface & & \\
\hline Upland-lowland interfaces & 146 & $0-508 \mathrm{~km}$ interface & & \\
\hline Sand movement corridors & $6^{\mathrm{i}}$ & $386-7959$ ha & & \\
\hline Inter-basin riverine corridors & 6 & $106-1520 \mathrm{~km}$ of corridor & & \\
\hline Upland-lowland gradients & 55 & $1-218 \mathrm{~km}$ & & \\
\hline Macroclimatic gradients & $3^{\mathrm{j}}$ & $263-617 \mathrm{~km}$ & & \\
\hline
\end{tabular}

a BHU targets were set for the total area of the BHU, ignoring loss of native vegetation.

b Accounts for different patterns of biological heterogeneity within BHUs.

c Accounts for different levels of threat to the remaining natural vegetation of each BHU.

d Includes an upward adjustment of targets for 17 BHUs to reduce the risk of target achievement only or mainly within edaphic and uplandlowland interfaces.

e Accounts for vulnerability of species to fire-induced population extinction.

${ }^{\mathrm{f}}$ Accounts for different levels of threat to the populations of each species.

g Accounts for global patterns of distribution, Red Data Book status and other factors (see Kerley et al, 2003, and text for details).

h Only extant areas of spatial components were targeted. Transformed areas comprise a restoration target (see text and Pressey et al., 2003).

${ }^{i}$ One of the seven mapped sand movement corridors was not targeted.

j Only gradients in the uplands were incorporated (see text). 
truncated them to present extant areas where necessary. We derived the extant areas of BHUs by excluding areas transformed by agriculture and plantations (hereafter "agriculture"), urban areas and stands of high density alien plants (invasive species of Acacia, Eucalyptus, Hakea, Leptospermum and Pinus-Richardson et al., 1992). This information came from mapping by Lloyd et al. (1999) using 1998 satellite data.

We derived total targets in hectares for BHUs by summing the baseline and retention targets and the upward adjustments to account for interfaces. Total targets represented between 10 and $55 \%$ of total BHU areas (Table 2). For 12 BHUs, total targets exceeded extant areas by between 102 and $416 \%$, indicating the need for restoration to address shortfalls (see Section 5.5 and discussion of restoration issues in Pressey et al., 2003).

\subsubsection{Proteas and vertebrates}

We also set baseline and retention targets for proteas and vertebrates, framed as numbers of populations, and based on the same principles as the BHUs (Pressey et al., 2003) (Table 2). The baseline target for proteas was five populations except for non-sprouting species with $<50$ populations. Since populations of non-sprouting species are vulnerable to fire-induced local extinction (Bond et al., 1984), we set a baseline target of 10 populations for those with small total populations in order incorporate more populations in conservation areas where the fire regime can be managed for achieving biodiversity goals. For vertebrates, we allocated a baseline target of one population per species.

For both taxon groups, we derived retention targets for species based on the threat profiles of populations across agriculture, alien plants and urbanisation (see Pressey et al., 2003, for details). We allocated retention targets to ensure that at least five records of each protea species and one record of each vertebrate species, in addition to the respective baseline target, was secure from threats. We truncated final targets (baseline + retention) to the total number of populations where necessary. Final targets for proteas varied from one to 15 populations; for vertebrates these were either one or two populations (Table 2).

\subsubsection{Large and medium-sized mammals}

Targets for the 41 species were set as numbers of individuals and based on a variety of criteria (Kerley et al., 2003). We summarise these here by placing species in four groups:

1. Three species (cheetah Acinonyx jubatus, gemsbok Oryx gazella and warthog Phacochoerus aethiopicus) with only marginal occurrences in the CFR and with no Red Data Book status (Smithers, 1986) had targets set to zero. These species can be more effectively protected in other regions.
2. Three species (bontebok Damaliscus dorcas dorcas, Cape mountain zebra Equus zebra and grysbok Raphicerus melanotis) that are endemic or near-endemic to the CFR had targets set to 2000. The persistence of these species is entirely reliant on conservation action within the region. The target is an approximation of the minimum population size necessary for a population to maintain evolutionary processes such as mutation (Lacy, 1997).

3. Four species of large carnivores with historical ranges widely distributed within and without the CFR. Targets for these species were intended to contribute to their wider conservation in southern Africa. Three of these large carnivores (brown hyaena Hyaenna brunnea, lion Panthera leo and spotted hyaena Crocuta crocuta) had targets set to 50, an approximation of the minimum size necessary for a population to persist despite demographic stochasticity (Caughley, 1994). The African wild dog Lycaon pictus is of high conservation concern (Smithers, 1986) and potentially occurred throughout most of the CFR (Boshoff and Kerley, 2001), albeit at very low densities. The national conservation strategy calls for the management of this species as a metapopulation of "tiny populations" (Woodroffe and Ginsberg, 1997) dispersed throughout South Africa, focusing on suitable habitat with a high density of prey species (Woodroffe and Ginsberg, 1997; Mills, 1997), a condition that is best achieved outside the CFR. The targets for this species were therefore set at 10 .

4. All remaining species had targets set to 200, an approximation of the minimum size necessary for a population to reduce genetic problems such as inbreeding (Caughley, 1994). This target level is based on the assumption that the CFR will make a contribution to the wider conservation of these species.

\subsubsection{Spatial components of processes}

In order to promote the persistence of ecological and evolutionary processes (Cowling and Pressey, 2001), we targeted the entire extent of their spatial components (Pressey et al., 2003), except for those parts under urban development. For the four spatially fixed components (Section 3.2.4), we recorded the extent to which the native vegetation in each component had been transformed by urbanization, agriculture and high density alien plants. Our extant target was the remaining untransformed area of each. This ranged from 0 to 120 $\mathrm{km}$ for edaphic interfaces, 0 to $508 \mathrm{~km}$ for upland-lowland interfaces, and 106 to $1520 \mathrm{~km}$ for whole interbasin riverine corridors (Table 2). Transformation of 
these components has incurred a restoration debt. In each case, the restorable target was the whole length of each component outside urban areas; we regarded portions of spatial components that were included within urban areas as non-restorable. In the case of sand movement corridors, we also identified any major (national and provincial) roads that crossed corridors. We targeted the four corridors that are potentially functional with some restoration. We considered sand movement corridors as functional if more than $50 \%$ of each section (upwind, core, and downwind) remained untransformed. We also targeted two other corridors that are crossed by major roads even though sand movement presents problems for transport. We did not target the easternmost corridor because the city of Port Elizabeth now extends substantially onto its downwind end.

We did not set targets for upland-lowland or macroclimatic gradients. Instead, we used the results of our preliminary path analyses as guidelines for planning decisions, in some cases altering the paths of gradients to link existing or proposed conservation areas and to achieve targets for other features.

\subsection{Planning unit layer}

Planning units (also called selection units), which consist of a priori subdivisions of the landscape, are routinely used in conservation planning (Pressey and Logan, 1998). Reserve selection algorithms, such as those embedded in C-Plan (see Section 3.6.1), assess the importance of each planning unit for achieving pre-defined conservation targets, such as those identified in this study.

In this study we developed a planning unit layer comprising arbitrary grid cells, statutory and non-statutory reserves, and fixed spatial components for processes. We based the planning units on sixteenth-degree squares (SDS, approximately 3900 ha). This initial size gave us a tractable number of units to assess across the region and is an appropriate scale for broad-scale planning, although not for implementation (see Section 5.4). In order to better assess the contribution of existing protected areas to target achievement, we used the exact configuration of statutory reserves as planning units. For non-statutory reserves (which are underpinned by weaker protection status), we retained their configuration but subdivided them according to sixteenth-degree squares. This enabled us to select only those parts of non-statutory reserves that contribute most to target achievement. We also incorporated the exact configuration of fixed process components (edaphic interfaces, riverine corridors, sand movement corridors, and upland-lowland interfaces) into the planning unit layer rather than generalising their boundaries to sixteenthdegree squares. We used the extant portions of these components, subdivided by the boundaries of sixteenthdegree squares, as process planning units. This con- siderably improved the efficiency of the conservation plan in terms of the total area required to achieve targets.

The planning unit layer thus consisted of 7039 planning units including 3014 sixteenth-degree squares (incorporating $74.5 \%$ of the extant area of the planning domain), 2993 process planning units $(6.2 \%), 122$ statutory reserve units $(10.1 \%)$ and 910 non-statutory reserve units $(9.2 \%)$. We did not consider flexible process components (upland-lowland gradients and macroclimatic gradients) as planning units, since there were spatial options for locating them.

\subsection{Data matrices}

We compiled the main data matrix to record, for each planning unit, the area of each BHU, the number of populations of each species of protea and vertebrate, the number of individuals of each species of large and medium-sized mammal, and the area of each fixed process component. We recorded only the areas currently untransformed (i.e. available for planning) for BHUs and fixed process components. The resulting data matrix consisted of 7039 planning units and 1018 biodiversity features (Table 2): 102 BHUs, 364 proteas, 345 vertebrates, 41 large and medium-sized mammals, and 166 fixed process components. We used C-Plan, a conservation planning software package (see Section 3.6.1), to calculate the importance of each planning unit for achieving the conservation targets for these features.

In order to guide the selection procedure, we also derived another data matrix that recorded tenure and information on threats to biodiversity for each planning unit. This information could be queried at any time during the selection process (see Section 3.6.7). Predicted threats were those arising from three sources: (i) agricultural transformation; (ii) urbanization; and (iii) the establishment of stands of alien trees and shrubs, notably species of Pinus, Acacia, Hakea, Eucalyptus and Leptospermum, all of which severely affect the structure and function of many CFR ecosystems (Richardson et al., 1992). Details on predicting the future spatial patterns of these threats are given in Rouget et al. (2003a). Each planning unit, excluding statutory reserves, was given a category (high, medium, low) according to its vulnerability to each of the three threats (see Rouget et al., 2003a, for method). Each planning unit was also given a category for maximum threat across the three sources of transformation.

\subsection{Planning protocol}

In developing the conservation plan, our aim was to achieve targets for all of the biodiversity features listed earlier. The integrated plan represents one option for conserving the biodiversity of the CFR. While we anticipated that the plan would require a large portion of the CFR (see Cowling et al., 1999b), we felt it 
important to present an outcome independant of the socio-economic factors that are likely to constrain implementation (see Section 5.4).

We developed the conservation plan in six stages that built on the existing statutory reserves. In the first three stages, we incorporated planning units for which - at least for this exercise - there were no alternative options for achieving targets, options for large and medium-sized mammals having been already considered and resolved (Kerley et al., 2003). In the last three stages, we incorporated planning units for which options did exist for achieving targets. The stages are described as follows.

\subsubsection{Stage 0: statutory reserves}

The starting point was to accept all statutory reserves as part of the conservation plan. Although the existing statutory reserve system is biased in favour montane BHUs (Rouget et al., 2003b), considerable investment has been made in its establishment and management (Cowling and Pressey, 2003). For practical purposes, the existing system of statutory reserves is fixed and we therefore incorporated it into the plan de facto. Owing to the uncertain legal status and institutional support for non-statutory reserves, we did not build them into the plan at this stage. Instead, they were considered as options for design in stages 4-6 of the protocol (see Sections 3.6.5-3.6.7).

We used conservation planning software, namely C-Plan (Pressey, 1999; Ferrier et al., 2000), which runs with the GIS software ArcView (ESRI, Redlands, California), to assess the contribution of the statutory reserve system to achieving targets for BHUs, proteas, vertebrates and fixed process components. One of C-Plan's outputs is a map of irreplaceability. Irreplaceability is a measure, varying from zero to one, which indicates the importance of an area (planning unit) for the achievement of regional conservation targets (Ferrier et al., 2000). Irreplaceability is defined as the likelihood of an area being required to achieve a set of targets or, conversely, the likelihood of one or more targets not being achieved if the area is unavailable for conservation action. A map of irreplaceability values is therefore a map of planning options. With progressively lower irreplaceability, the number of possible replacements for an area increases. Using the targets for the features listed above, irreplaceability was calculated for all planning units outside statutory reserves.

\subsubsection{Stage 1: fixed process components}

Planning units comprising extant areas of the four spatially fixed process components - edaphic interfaces, upland-lowland interfaces, sand movement corridors and inter-basin riverine corridors - were incorporated as the first stage of the emerging conservation plan. Given that the entire extant areas of these processes were targeted, all of these planning units had maximum irreplaceability in the C-Plan analyses. Stage 1, in addition to the existing statutory reserves, therefore, provided a framework on which to build the later stages of the plan.

\subsubsection{Stage 2: planning units of maximum irreplaceability} for achievement of $B H U$, protea and vertebrate targets

Next we incorporated in C-Plan all planning units that had maximum irreplaceability for the achievement of BHU, protea and vertebrate targets. All of these planning units include one or more biodiversity features (extant area of BHUs, populations of proteas and vertebrates) that were essential for target achievement.

\subsubsection{Stage 3: Conservation plan for large and medium- sized mammals}

This stage incorporated a conservation plan, developed in C-Plan, for achieving targets for large and medium-sized mammals (Kerley et al., 2003). They provide details on how this plan was developed; we present only a summary here.

Kerley et al. (2003) analysed the data on distributions and densities of the mammal species to produce the data set for the conservation plan. They excluded areas that had been transformed by agriculture, alien plants and urbanisation. They then identified minimum numbers of individuals in species or species categories needed for functional social or breeding groups or effective management, assuming that conservation agencies will manage the exchange of individuals of some species between conservation areas. In each fragment of native vegetation in the region, any species with fewer estimated individuals than its specified minimum had its numbers set to zero. This focused the conservation plan on areas containing substantial portions of the target for each species and where breeding and social groups could operate.

Two other considerations were important in developing a conservation plan for these species (see Kerley et al., 2003, for details of method). First, it was a requirement that conservation areas identified for the plan, whether or not they included existing reserves, should support at least the specified minimum numbers if they were to contribute to targets. Second, individual conservation areas were designed to contain complementary habitats required by some species. An example is the Cape mountain zebra that inhabits mountains but moves onto lowlands seasonally (Boshoff et al., 2001).

Kerley et al. (2003) produced a map of irreplaceability for achieving the mammal targets. This, and a set of rules, provided in Kerley et al. (2003), guided them in identifying a system of conservation areas.

\subsubsection{Stage 4: macroclimatic gradients}

In this stage, we selected planning units to complete the three macroclimatic gradients in the uplands (i.e. north-south in the coastal mountains; east-west in the 
coastal mountains; east-west in the interior mountains, see Rouget et al., in press). By the end of stage 3, we had incidentally completed the north-south gradient. Guided by the paths described in Section 3.2.4, we applied the following rules for completing the two remaining (east-west) gradients:

1. maximise the length of the gradient in Mountain Fynbos Complex BHUs in order to ensure biologically feasible transitions (i.e. those that did not involve abrupt edaphic and climatic transitions) between adjacent habitats;

2. minimise the length in lowland habitats where uplands are fragmented into stepping stones at the western end of the east-west gradient in the interior mountains;

3. where possible, incorporate statutory reserves and areas selected in earlier stages in the planning process;

4. where possible, incorporate units of higher irreplaceability for the achievement of other targets;

5. where possible, incorporate non-statutory reserves; and

6. avoid transformed areas.

\subsubsection{Stage 5: upland-lowland gradients}

In this stage we considered the 85 upland-lowland gradients (Rouget et al., in press). Guided by the paths described in Section 3.2.4, we applied the following rules for selecting suitable gradients:

1. avoid biologically unfeasible transitions involving abrupt changes in soil fertility, $\mathrm{pH}$ and moisture across BHU boundaries, i.e. between Mountain Fynbos Complex and either Succulent Karoo, Nama Karoo or Coast Renosterveld BHUs (Cowling and Holmes, 1992; LechmereOertel and Cowling, 2001); between Limestone Fynbos and all other BHUs (Richards et al., 1997); and between Coast Renosterveld and all other BHUs except Grassy Fynbos and Fynbos/Renosterveld Mosaic (Cowling and Holmes, 1992); and

2. apply rules 3-6 in Section 3.6.5.

Consequently, we discarded unfeasible paths (or potential gradients), while others were shortened to avoid infeasible transitions, or redirected to incorporate statutory reserves and areas selected in earlier stages in the planning process.

\subsubsection{Stage 6: final design}

In the final design stage of the planning process, we selected planning units to achieve all outstanding targets for BHUs, proteas and vertebrates. In order to identify the most efficient solution that minimised the inclusion of highly threatened areas (and, consequently, high opportunity costs for conservation), we undertook two trial stepwise minimum set analyses (minsets) to identify indicative sets of sites for consideration. A stepwise minset analysis uses a sequence of rules iteratively to select the minimum or near-minimum (Underhill, 1994) number of planning units that will satisfy all biodiversity targets. We executed the minsets in C-Plan, using summed irreplaceability as the measure of site contribution to target achievement (Ferrier et al., 2000). Summed irreplaceability is calculated by adding the irreplaceability values of each planning unit for each of the features it contains; unlike site irreplaceablity, values may be $>1$. High values indicate that the planning unit is important in achieving conservation targets for several features.

We used two minsets for the indicative analyses. The first minset had two rules:

1. select the planning unit with the highest summed irreplaceability; and

2. if there is a tie in rule 1 , select the first planning unit on the list.

This minset selected 148 planning units (rule 2 was only used once).

The algorithm in the second minset was designed to minimise conflict between achieving targets and confronting threats. The rule sequence was as follows:

1. select all sites in the top $5 \%$ of current summed irreplaceability values (this rule was designed to ensure that rule 2 would be used);

2. if there is a tie in rule 1 (guaranteed), select the planning unit of lowest maximum threat;

3. if there is a tie in rule 2 , select the planning unit with the highest summed irreplaceability; and

4. if there is a tie in rule 3, select the first planning unit on the list.

This minset selected 154 planning units as opposed to the 148 selections in the first one. Therefore, minimising threats involved little cost in efficiency. Consequently, we used the results of the second minset in guiding our selections for the final design stage of the planning process.

The algorithm we used has limited value for making design decisions since it only incorporated tradeoffs between two considerations, namely irreplaceability and threats. In reality, there are numerous other area-specific considerations in designing conservation areas, including rationalisation and expansion of boundaries of statutory reserves and selections from earlier stages in the planning process, achieving improved design for spatial components of processes, and selecting areas where there are existing conservation initiatives (e.g. non-statutory reserves) (Groves et al., 2000; Margules 
and Pressey, 2000; Noss et al, 2002). We attempted to incorporate these multiple considerations into the design by applying intuitively the following set of rules:

1. locate units selected by the second minset;

2. if adjacent to previously reserved area, then accept;

3. if not, then choose an alternative based on maximising irreplaceability and minimising threat; and

4. where there were choices for rule 3, either:

- buffer process components; or

- choose non-statutory reserves.

In summary, in the final design stage we sought to minimise conflict between achieving targets and threats, and then adjusted these selections as appropriate to achieve sensible design based on expanding the existing reserve system, strengthening the conservation of processes, and aligning selections with existing off-reserve conservation initiatives.

\section{Results}

\subsection{The integrated plan}

The integrated plan (Fig. 1) covered $49,958 \mathrm{~km}^{2}$ of extant habitat of which $9686 \mathrm{~km}^{2}(19.4 \%)$ comprised statutory reserves. It incorporated $52.3 \%$ of the 95,579 $\mathrm{km}^{2}$ of extant habitat in the planning domain (Fig. 2), and $42.1 \%$ excluding statutory reserves. Excluding the statutory reserves (stage 0 ), extant land requirements were highest for the mammal conservation plan (stage 3) $(16.2 \%$ of total $)$ and units of maximum irreplaceability (stage 2) $(9.4 \%)$, and lowest for the addition of macroclimatic $(1.5 \%)$ and upland-lowland $(3.6 \%)$ gradients (Fig. 2).

\subsection{Description of planning stages}

In this section we provide a brief summary of each of the planning stages in terms of extant area required (Fig. 2), their geographical location within the planning domain (Figs. 1, 3 and 4), and target achievement for BHUs, proteas and vertebrates (Fig. 5).

\subsubsection{Stage 0: statutory reserves}

Statutory reserves comprised $10.1 \%$ of the planning domain's extant area (Fig. 2). They are largely concentrated in Mountain Fynbos Complex BHUs of the uplands (see Rouget et al., 2003b, for details on spatial biases in the statutory reserve system). These reserves achieved the targets for $15.6 \%$ of BHUs, $67.0 \%$ of proteas and $82.6 \%$ of vertebrates (Fig. 5). At this stage, zero target achievement was recorded for 20 BHUs, 73 proteas and 49 vertebrates.

\subsubsection{Stage 1: fixed process components}

These spatial components encompassed $6.2 \%$ of the planning domain's extant area (Fig. 2). They were located throughout the planning domain, as determined by the location of the physical features with which they are associated. Their inclusion in the plan increased the percentage target achievement for features as follows: BHUs $-10 \%$, proteas $-4.1 \%$, vertebrates- $0.8 \%$ (Fig. 5). At this stage zero target achievement was recorded for two BHUs, 49 proteas and 45 vertebrates.

\subsubsection{Stage 2: planning units of maximum irreplaceability for achievement of $B H U$, protea and vertebrate targets}

Planning units of maximum irreplaceability for features other than process components comprised an additional $9.4 \%$ of the planning domain's extant area (Fig. 2). Most of these were located on the lowlands, especially western, south-western and south-eastern parts of the planning domain, where they were associated with the 12 BHUs with targets $>100 \%$ of extant habitat. These BHUs fall into two broad categories. The first consists of coastal BHUs on sandy soils - mainly forms of Fynbos/Thicket Mosaic (Cowling and Heijnis, 2001) - in the southwest (near Cape Town) and the southeast (near Port Elizabeth), where urbanization and alien plants are major agents of transformation, and pose a serious threat to the remaining extant habitat. In the second category are coastal lowland BHUs on fertile soils - mainly forms of Coast Renosterveld and Fynbos/ Renosterveld Mosaic (Cowling and Heijnis, 2001) - in the southwest and south, where agriculture has transformed most of their extent and remains a threat to the remaining habitat (Rouget et al., 2003a). Consequently, most of these maximally irreplaceable planning units include only small fragments of extant habitat.

A much smaller number of planning units, most of which are isolated and located in a matrix of units of moderate to low irreplaceability (Fig. 3), owe their maximum irreplaceability status to their importance for achieving targets for proteas and vertebrates.

Except for statutory reserves (stage 0 ), stage 2 predictably made the most substantive contribution to target achievement for BHUs, proteas and vertebrates. The proportion of BHUs with $100 \%$ target achievement was increased from Stage 1 by 26.5 to $53.0 \%$. For proteas, the corresponding data were 25.9 to $97.0 \%$, and for vertebrates 14.5 to $97.9 \%$ (Fig. 5). Only one BHU, one protea and six vertebrates remained completely unreserved at the end of Stage 2.

\subsubsection{Stage 3: conservation plan for large and medium- sized mammals}

The mammal plan (Fig. 4) was the most land intensive of all stages in the conservation plan, requiring an additional $16.3 \%$ of the extant area of the planning domain 
(Fig. 2). The associated planning units were largely concentrated in untransformed areas of the southern coastal margin (where they achieved targets for the endemic bontebok), as well as upland areas adjacent to statutory reserves and in the Little Karoo interior basin (see Kerley et al., 2003). There were two main reasons for the large extent of areas added in this stage: the size of the targets for the mammals; and the need for large, connected conservation areas to promote the persistence of these species.
Despite incorporating such a large amount of additional habitat, this stage did not markedly improve the conservation status of the other biodiversity features. The proportion of BHUs with $100 \%$ target achievement was increased by only 9.6 to $66.6 \%$ (Fig. 5); this is because most of the selections were in upland BHUs for which targets had already been achieved by statutory reserves (stage 0). Complete target achievement improved only marginally for proteas (up by $1.4 \%$ ) and vertebrates

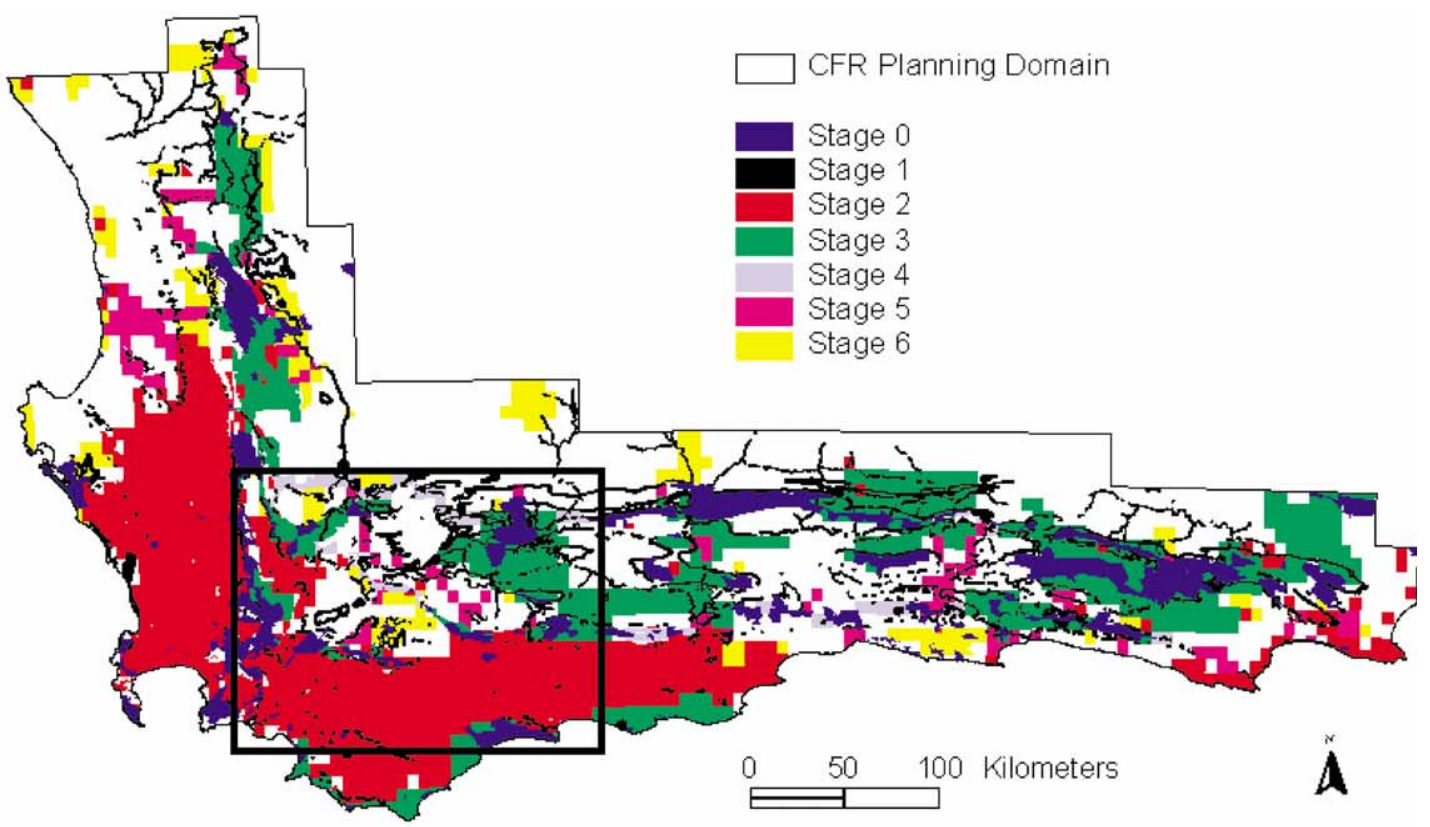

(a)

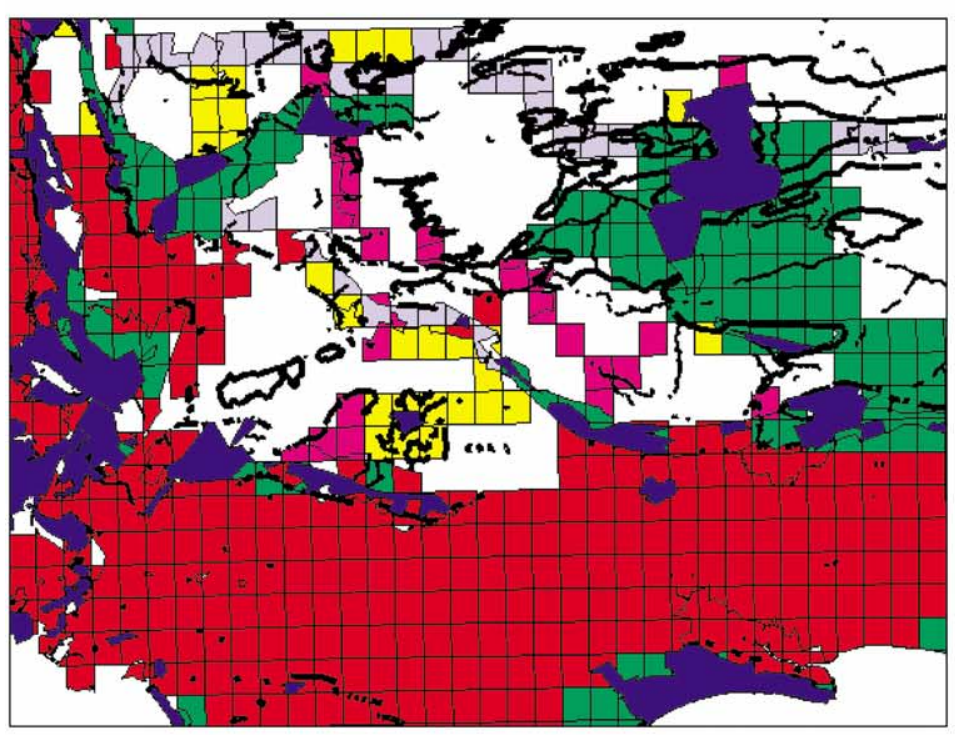

CFR Planning Domain

Stage 0

Stage 1

Stage 2

Stage 3

Stage 4

Stage 5

Stage 6

(b)

Fig. 1. Map of the planning domain for the Cape Floristic Region showing (a) a notional system of conservation areas that achieves targets for all biodiversity features. Different colours denote planning units selected for achievement of targets in six stages (S1-S6) building on the existing statutory reserves (stage 0). Inset in (a) is enlarged in part (b). 


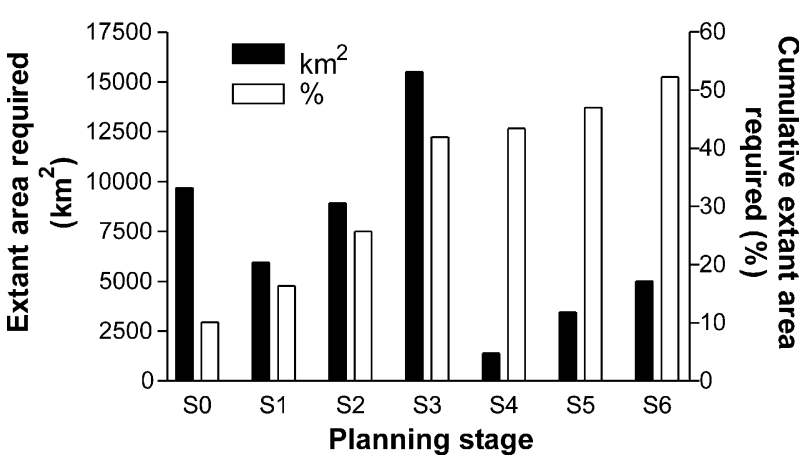

Fig. 2. Extant area of the planning domain for the Cape Floristic Region included in each stage (S0-S6) in the development of the notional conservation plan.

$(0.6 \%)$. At the end of this stage, only one BHU and three vertebrates remained completely unreserved.

\subsubsection{Stage 4 and 5: macroclimatic and upland-lowland gradients}

We selected these two process components using a similar set of design rules (see Sections 3.6.5 and 3.6.6); consequently, we grouped them in this summary. Together they incorporated an additional $5.1 \%$ of the extant area of the planning domain (Fig. 2). Their associated planning units were located throughout the planning domain. Although they were identified as $1-\mathrm{km}$-wide paths, we selected SDS planning units ( $>6 \mathrm{~km}$ wide) to include them in the plan (see Fig. 1b). Consequently, this stage was inefficient, relative to the fixed components, in terms of extant area selected.

At the end of this stage, the proportion of BHUs with $100 \%$ target achievement was increased by 8.9 to $75.5 \%$ (Fig. 5), proteas by 0.8 to $99.2 \%$, and vertebrates by 0.6 to $99.2 \%$. The number of unreserved features at the end of this stage was largely unchanged relative to stage 3 .

\subsubsection{Stage 6: final design}

The final design stage incorporated an additional $5.3 \%$ of the extant area of the planning domain (Fig. 2). With few exceptions, the selections expanded conservation areas identified in previous stages or comprised additional and relatively large-sized conservation areas. The latter were located on the coastal forelands of the northwest, in the north, and on the southern coast (Fig. 1). Our final design selected $45.3 \%$ of planning units chosen in the second minset.

By definition, this stage achieved outstanding targets for all features (Fig. 5). However, over-achievement of targets in the integrated plan was substantial, although values relative to stage 0 (statutory reserves) were variable across features (Table 3). For BHUs, 85 had values of $>150 \%$ target achievement compared with only 13 at stage 0 . The three highest values at the end of stage 6 were recorded for Mountain Fynbos Complex BHUs (Baviaanskloof - 694\%; Kouga-718.5\%; Groot Swartberg-933\%), all located towards the east of the planning domain and including much habitat required for the mammal conservation plan (Fig. 4; see also Kerley et

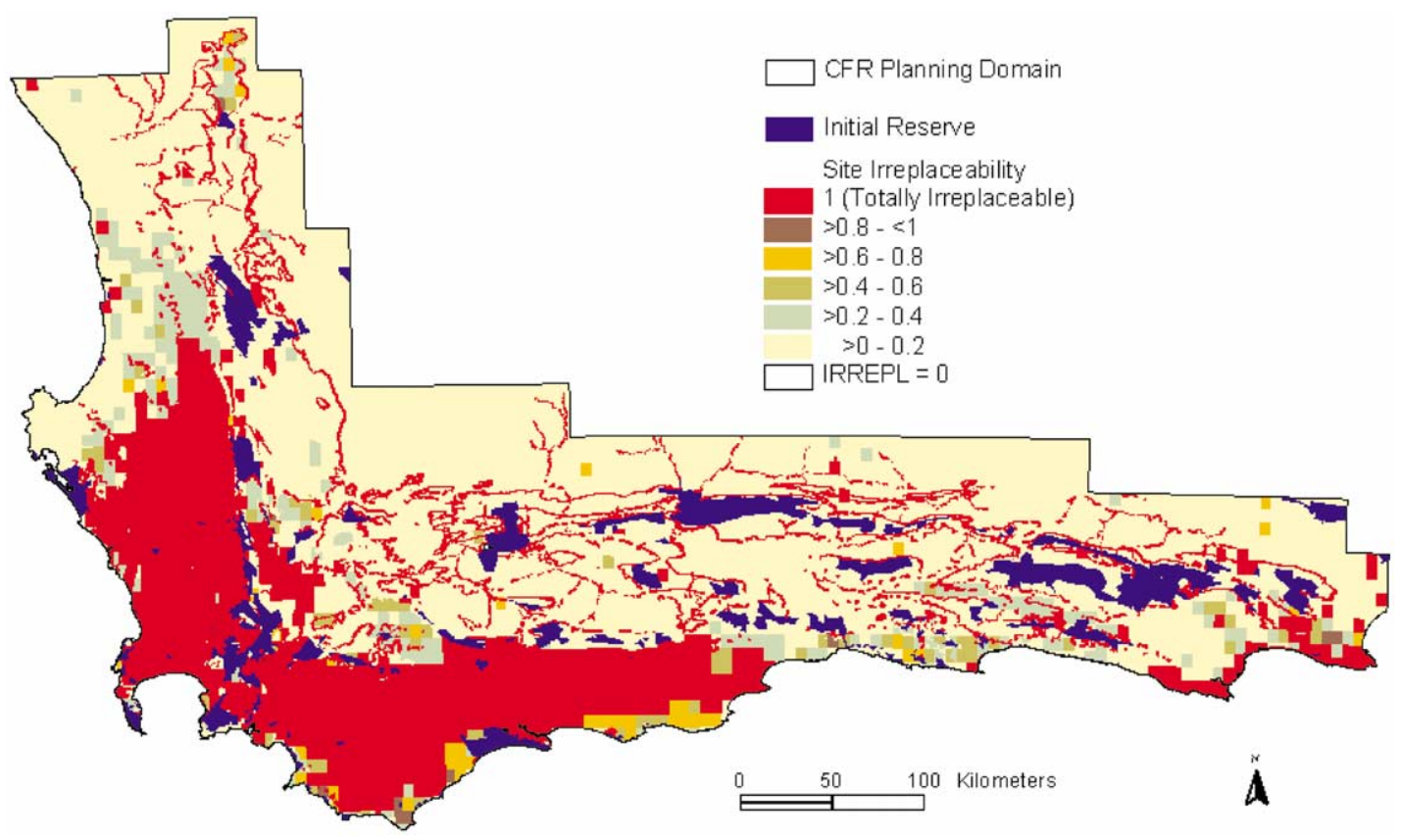

Fig. 3. Map of the planning domain for the Cape Floristic Region showing initial site irreplaceability of planning units for achieving targets for broad habitat units (BHUs), proteas, vertebrates and fixed process components (edaphic interfaces, upland-lowland interfaces, entire sand movement corridors, and whole inter-basin riverine corridors). Irreplaceability values account for the contribution of initial reserves (existing statutory reserves) to achieving targets. 


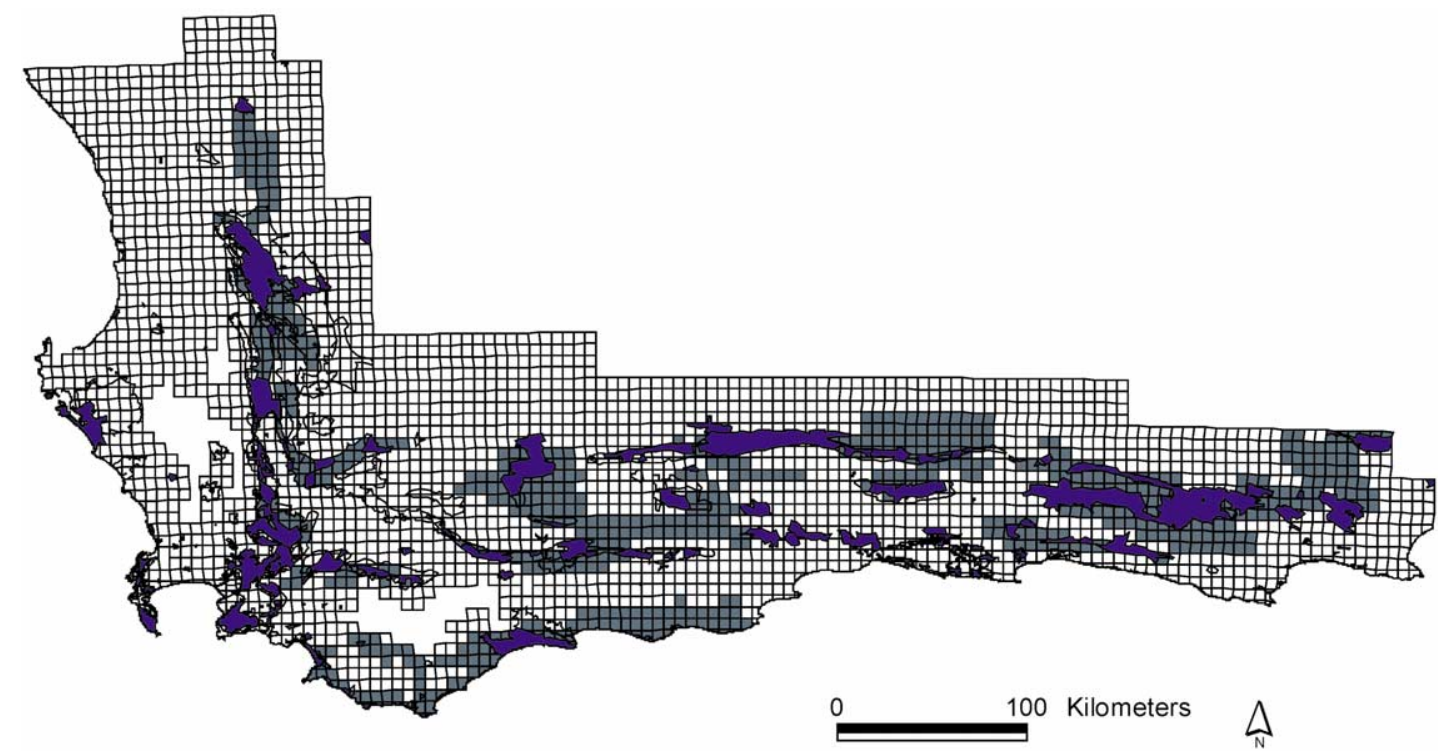

Fig. 4. The conservation plan for large and medium-sized mammals that was incorporated as stage 3 of the overall conservation plan for the Cape Floristic Region. Irregular, light-shaded planning units are statutory reserves; dark-shaded units are those additional areas selected by Kerley et al. (2003) to achieve targets for the 41 mammal species.
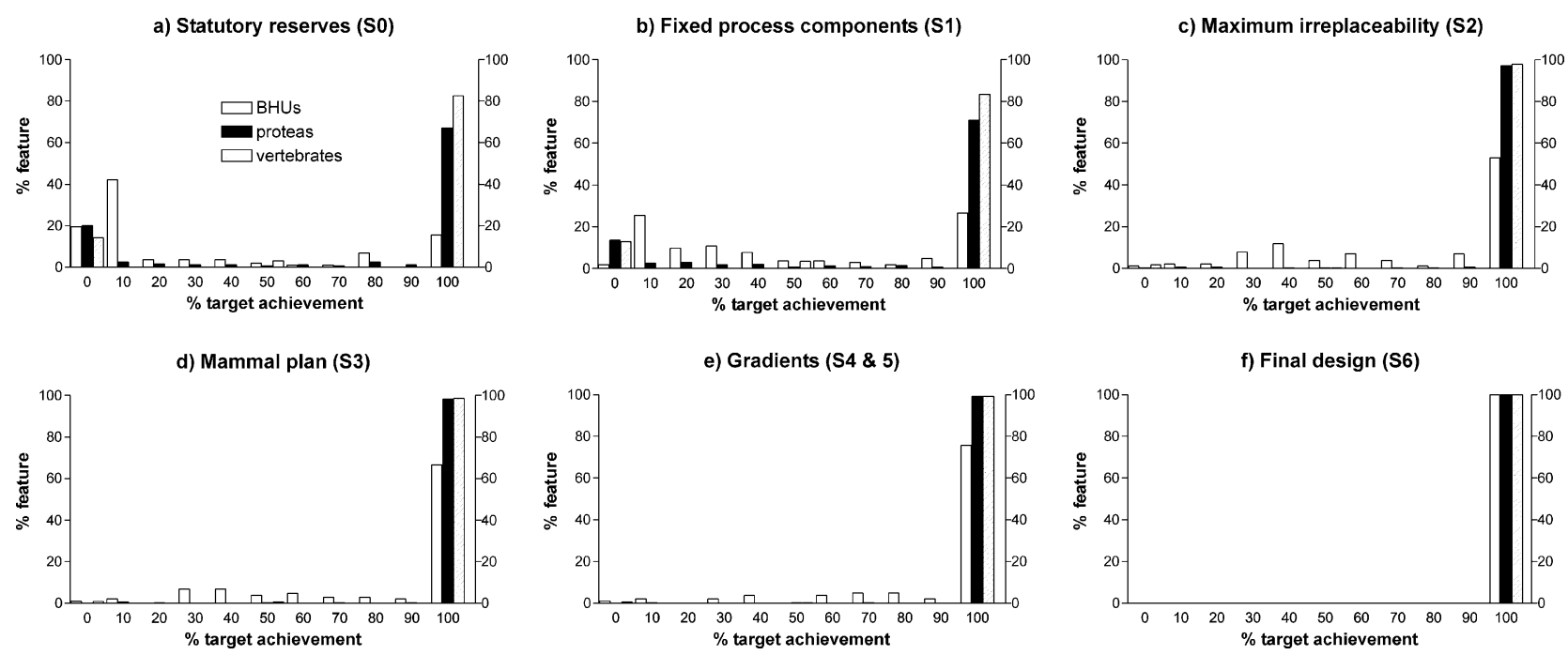

Fig. 5. Percentages of biodiversity features-BHUs (broad habitat units), proteas, vertebrates - in categories of target achievement at different stages (S0-S6) in the development of the notional conservation plan.

al., 2003). In the case of proteas, the discrepancy between the two stages was less: 238 species had values $>1000 \%$ at stage 0 compared with 318 in the final design. The three highest values were recorded for Protea nitida (5586 populations), P. laurifolia (6058) and Leucadendron salignum $(13,918)$; all of these species are widespread and common in the planning domain (Rebelo, 2001). The pattern for vertebrates was similar to proteas: 189 species had values $>1000 \%$ at stage 0 relative to 221 at stage 6 . The three highest values were recorded for freshwater species: the clicking stream frog Strongylopus grayii (202 populations), the Cape kurper Sandelia capensis (339) and the Cape galaxias Galaxias zebratus (355). The two fish species have wide habitat tolerances
(Skelton, 1993) and all three species are common and widespread along the coastal regions of the planning domain (Skelton, 1993; Carruthers, 2001).

\subsection{Summary of the integrated plan in relation to initial irreplaceability for pattern features}

Excluding statutory reserves, small extant areas of the three pattern features (BHUs, proteas and vertebrates) for which there were options for achieving targets, were associated with planning units of maximum irreplaceability: $8.9 \%$ of the planning domain for BHUs, and only $1.6 \%$ for proteas and $0.6 \%$ for vertebrates (Fig. 6). Most of the extant area of the planning domain comprised 
Table 3

Target achievement for biodiversity features at the first and last stages of a conservation plan for the Cape Floristic Region

\begin{tabular}{lcc}
\hline $\begin{array}{l}\text { Target achievement } \\
(\%)\end{array}$ & No. features \\
\cline { 2 - 3 } & $\begin{array}{l}\text { Stage 0-Statutory } \\
\text { reserves }\end{array}$ & $\begin{array}{c}\text { Stage 6-Final } \\
\text { design }\end{array}$ \\
\hline BHUs & \\
$<100$ & & \\
$\geqslant 100<150$ & 20 & 0 \\
$\geqslant 150>300$ & 69 & 17 \\
$\geqslant 300$ & 6 & 39 \\
Proteas & 7 & 46 \\
$<100$ & & \\
$\geqslant 100<1000$ & 73 & 0 \\
$\geqslant 1000<10,000$ & 53 & 46 \\
$\geqslant 10,000$ & 105 & 108 \\
Vertebrates & 133 & 210 \\
$<100$ & & \\
$>100<1000$ & 49 & 0 \\
$>1000<2500$ & 107 & 124 \\
$>2500$ & 119 & 94 \\
\hline
\end{tabular}

a $\mathrm{BHU}=$ broad habitat unit (Cowling and Heijnis, 2001).

planning units of very low $(<0.2)$ irreplaceability for these three sets of features. However, the integrated plan incorporated a large proportion of this terrain, namely $31 \%$ of the low irreplaceability area for BHUs, $38 \%$ of that for proteas and $54 \%$ for vertebrates. This over-representation of low irreplaceability area in the plan could be a consequence of (i) the coincidence between areas of low irreplaceability for these features and the areas required to achieve mammal and process component targets, and (ii) the over-achievement of targets for these features while achieving targets for mammals and process components.

\subsection{Options and threats}

To what extent were we successful in avoiding areas of high threat status while still achieving our conservation targets and a sensible design for the conservation plan? At stage 0 of the plan (statutory reserves), options for achieving targets for pattern features (BHUs, proteas and vertebrates) were greatest in areas of low and medium threat levels: $61.6 \%$ of the extant area of the planning domain, excluding statutory reserves, comprised planning units of low to medium threat status with corresponding irreplaceability values of 0.4 and less (Fig. 7a). On the other hand, $57 \%$ of the extant area in planning units of moderate to maximum irreplaceability $(>0.4)$ was associated with high threat status, indicating that many areas with least options for achieving targets were under greatest threat. The integrated plan (stage 6) differed little from stage 0 in terms of the extant area within planning units in the higher irreplaceability classes across all threat categories (Fig. 7b). This is not surprising since these areas, by definition, were either essential for achieving targets or highly likely to be required. Accordingly, all planning units of maximum irreplaceability were included in stages 1 and 2. However, in comparison with stage 0 , the plan included proportionately more area $(51.2 \% \mathrm{cf}$. $41.3 \%$ ) in units of low irreplaceability and medium to high threat status. Therefore, despite attempts to avoid high-threat planning units during the design stages of developing the plan, other important considerations necessitated selection of many of them. These considerations included achieving mammal population targets in high-threat lowland areas (Kerley et al., 2003), completing gradients, consolidating reserve design, and achieving outstanding targets for pattern features.

\section{Discussion}

\subsection{Overview of the plan}

Our plan required that in addition to the statutory reserves, $42 \%$ of the extant area of the CFR, comprising some $40,000 \mathrm{~km}^{2}$, be allocated some form of conservation management in order to promote the persistence of the region's documented biodiversity. The implementation of the plan is, according to our analyses, essential for achieving the goal of the Cape Action Plan for the a) BHUs

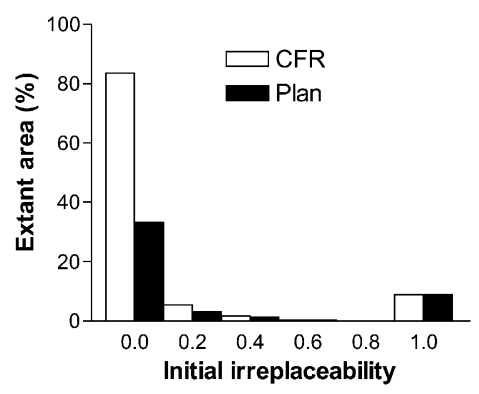

b) Proteas

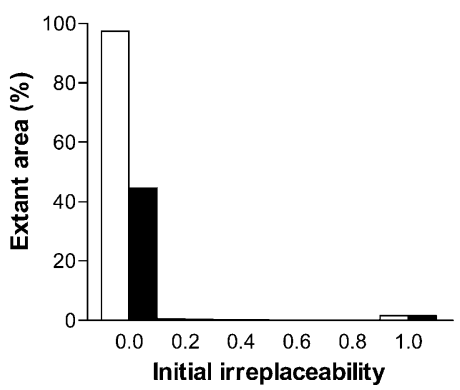

c) Vertebrates

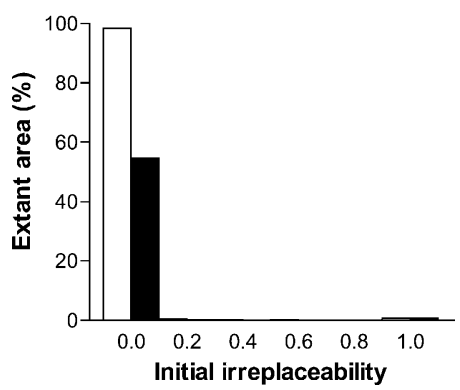

Fig. 6. Extant area (excluding statutory reserves) under different categories of initial irreplaceability (when $\mathrm{S}=0$ ) for different biodiversity features in the entire Cape Floristic Region planning domain and for the notional conservation plan. 
a)

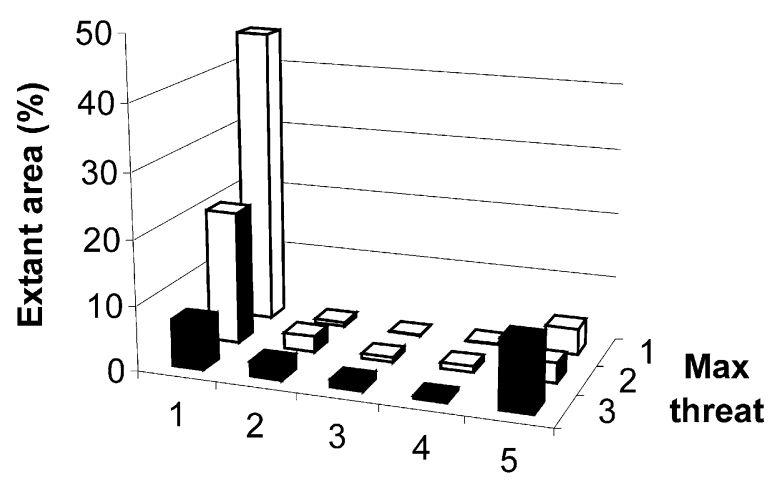

Irreplaceability

b)

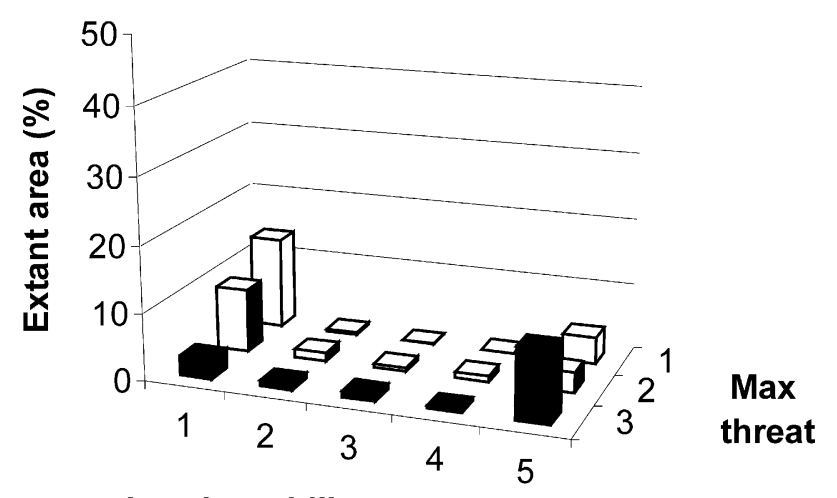

Irreplaceability

Fig. 7. Priority profiles of extant area, expressed as a proportion of extant area in the planning domain excluding statutory reserves, (a) for the entire Cape Floristic Region planning domain at $\mathrm{S}=0$, and (b) for the final notional conservation plan (at $S=6$ ). Maximum threat is reported as the highest score among the three threats (agriculture, alien plants and urbanization). Classes are: $1=$ low, $2=$ medium and $3=$ high. Irreplaceability values are for all pattern features (BHUs, proteas and vertebrates) and the fixed process components. Classes are: $1=\leqslant 0.2 ; 2=>0.2 \leqslant 0.4 ; 3=>0.4 \leqslant 0.6 ; 4=>0.6 \leqslant 0.8 ; 5=>0.8$.

Environment Project (CAPE), namely to achieve effective conservation of the CFR's biodiversity by 2020 (Lochner et al., 2003). There is increasing recognition that plans based on arbitrary targets of $10-12 \%$ of land classes or planning domains, are inadequate to ensure the effective conservation of a region's biodiversity (Rebelo, 1997; Soulé and Sanjayan, 1998; Groves et al., 2000; Margules and Pressey, 2000; Pressey et al., 2003). Indeed, recent conservation plans that have achieved rational targets for multiple features have required 60 $70 \%$ of the planning domain (Noss et al., 1999, 2002). Plans based on achieving targets for single sets of features usually require much less land. For example, using SDS and statutory reserves as planning units, Lombard et al. (2003) found that only $12 \%$ of the extant area of the CFR was required to conserve one occurrence of each protea and vertebrate species, rising to $15 \%$ for five occurrences (see also Rebelo and Siegfried, 1992).

The configuration of the integrated plan was more strongly influenced by some of its components than others. These were: (i) the existing statutory reserve system that overachieved targets for many montane BHUs (Rouget et al., 2003b), achieved targets for most proteas and vertebrates (Lombard et al., 2003), and constrained the design for the mammal plan (Kerley et al., 2003) and gradients; (ii) target achievement for the 12 BHUs in high-threat landscapes for which all remaining extant habitat was required; and (iii) the large area of additional habitat of montane BHUs required to achieve mammal population targets. As a result, large tracts of extant habitat of low irreplaceability for BHUs, proteas and vertebrates was included in the plan, and targets for some of these features were massively over-achieved. Despite attempts to avoid high-threat planning units in the design stages of the plan, many of these were required to achieve pattern feature targets (especially for some highly transformed BHUs) and incorporate entire process components on the lowlands.

Although our targets were ambitious (Pressey et al., 2003), they did not explicitly include much unmapped and unknown biodiversity. For example, we have no way of assessing the extent to which the plan incorporated invertebrates, the most diverse and poorly known group of terrestrial organisms globally (Hammond, 1992; Redak, 2000), as well as in the CFR (Picker and Samways, 1996). Like the vertebrates (Lombard et al., 2003), the distributions of some invertebrate taxa may be linked to historical rather than contemporary ecological patterns (Enrödy-Younga, 1988); we do not know how many localities of these taxa were captured in the plan. However, some invertebrate taxa have distributions that are strongly associated with vegetation patterns (Colville et al., 2002) or particular protea species (Wright and Samways, 1999); our plan may have been effective in representing these. Another aspect of biodiversity not explicitly targeted in the plan was genetic diversity within taxa, although the incorporation of process components, especially gradients and interfaces, may have captured both the adaptive and historical dimensions of genetic diversity for many taxa (Poiani et al., 2000; Moritz, 2002).

With the exception of the proteas and vertebrates (including mammals), we targeted land classes as surrogates for taxa. Proteas are good surrogates for other Cape clades (Rebelo and Siegfried, 1990) but not for taxa associated with the enclaves of non-fynbos vegetation in the planning domain (Cowling and Heijnis, 2001). We used inferred patterns of plant turnover and a precautionary, retention component to set targets for BHUs - which strongly influenced planning outcomes- 
and identified spatial surrogates for processes. It would have been more desirable to target more taxa, as well as more areas of known importance for genetic divergence and variability. Given the paucity of data and constraints, within the time frame of the planning exercise, on accumulating additional distributional and phylogeographic data for most taxa, the use of surrogates was a practical and realistic option. Future research here as well as in other global priority ecoregions should focus on refining biodiversity surrogates as pattern and process features for conservation planning (see Ferrier, 2002).

The suite of sites identified in the integrated plan is one of numerous alternatives; the eventual configuration of the plan will depend on the implementation of the two stages in the plan where options exist for target achievement, namely the mammal plan and the location of the upland-lowland and macroclimatic gradients. The decision support system that we have used provides the requisite flexibility for identifying alternative configurations subject to implementation constraints (Pressey, 1999; Pressey and Taffs, 2001).

\subsection{Assessment of the planning approach}

Our planning approach includes widely-used as well as novel elements of ecoregional planning. In developing the plan, we followed the six steps for systematic conservation planning outlined by Margules and Pressey (2000) (see Cowling and Pressey, 2003). Despite the shortcomings of the existing statutory reserve system in representing pattern and process features (Rouget et al., 2003b), we incorporated it into the plan-a common practice (e.g. Rebelo and Siegfried, 1990; Groves et al., 2000). We also incorporated expert knowledge in all stages of the planning process, including the development of the plan (Groves et al., 2000; Noss et al., 2002).

In many respects, our approach was consistent with the shift from species-based approaches of the 1970s and 1980s to the ecosystem approach of the 1990s, pioneered by Noss and colleagues in the USA (Schwartz, 1999; Poiani et al., 2000). We sought to achieve targets for coarse-filter features such as land classes and environmental gradients, and also identified areas for protecting viable populations of large herbivores and top carnivores (Terborgh and Soulé, 1999; Terborgh et al, 1999; Carroll et al., 2001; Noss et al., 2002). We developed our reserve system by initially incorporating sites of maximum irreplaceability for achieving targets for both coarse-filter (BHUs, fixed process components) and fine-filter (species records) features. Consequently, the plan incorporated many small habitat fragments, slivers of landscape, and isolated planning units that included populations of rare proteas and vertebrates. The use of the extremely comprehensive protea data set enabled us to identify sites important for the conservation of rare taxa that were likely to be overlooked (Kirkpatrick and Gilfedder, 1995; Lombard et al., 2003). We also identified large tracts of intact habitat suitable for the conservation large mammals, but which also contributed, albeit not substantially, to target achievement for other features (Kerley et al., 2003).

We explicitly incorporated a persistence goal (Cowling et al., 1999a; see Section 5.3) by targeting entire process components and viable mammal populations. Where no options existed - as was the case for the spatially fixed interfaces, sand movement corridors and riverine corridors, we targeted the associated planning units in their entirety. For the flexible gradient components, we used least-cost paths as guidelines but varied these for the plan to avoid biologically unfeasible transitions, incorporate existing conservation initiatives, achieve targets for other features, and avoid transformed areas. We know of no other ecoregional plans that have adopted this approach. Although many entire process components or sub-components were located in transformed, lowland landscapes, these were nonetheless incorporated into the plan. We reasoned that the retention of these components was essential for the long-term persistence and ongoing diversification of the CFR's biota (Cowling and Pressey, 2001); persistence could not be achieved by focusing only on large tracts of intact habitat.

Our simultaneous focus on transformed and intact landscapes has pros and cons. Implementation and management of large reserves is far less costly than conserving isolated fragments in a biodiversity-hostile matrix (Frazee et al., 2003). However, in the CFR and elsewhere, transformed landscapes include unique biodiversity features that must be afforded some form of protection in order to realise conservation goals (McDowell and Moll, 1992; Hobbs, 1993; Pressey et al., 1996; Kemper et al., 2000). There is also an issue of the scale of biodiversity pattern and process in different ecoregions (Schwartz, 1999). While protected areas of $>1000$ ha might be regarded as having low conservation value in some parts of the world (e.g. Noss and Cooperrider, 1994), in the CFR areas much smaller than this can accommodate a wide range of biodiversity patterns and processes if appropriately managed (Bond et al., 1988; Cowling and Bond, 1991; Kemper et al., 1999).

Finally, our approach represents another model for integrating data and software with expert judgement (see Noss et al., 2002, for an alternative). In the final stage of the planning process, we used an algorithm that selected sites to achieve outstanding targets for multiple features and simultaneously avoid those that were vulnerable to threatening processes (see also Howard et al., 2000) - an example of how algorithms can be used for more complex problems than just representation (Rodrigues et al., 2000). We then used 
expert judgement - embedded in a set of rules - to select from the minset those planning units that expanded existing statutory reserves, buffered process components and incorporated existing off-reserve conservation initiatives.

\subsection{Planning for persistence}

The ultimate goal of conservation planning is to ensure the persistence of the regional biota (Pressey and Logan, 1998; Cowling et al., 1999a; Margules and Pressey, 2000; Moritz, 2002). Persistence can be incorporated into the planning processes through an understanding of the ecological and evolutionary processes that maintain and generate biodiversity (Smith et al., 1993; Dimmick et al., 1999; Foster, 2000), and the depiction of these processes spatially (Smith et al., 1997; Fjedså and Rahbek, 1998; Moritz and Faith, 1998; Balmford et al., 1998; Cowling et al., 1999a; Desmet et al., 2002). This is not a trivial task (Balmford et al., 1998). Up until relatively recently, concerns about persistence in conservation biology have been generally limited to internal dynamics of small and isolated populations (e.g. Caughley, 1994) and generic design criteria (Pressey et al., 2003). From a conservation planning perspective, several studies (e.g. Margules and Stein, 1989; Williams and Araújo, 2000) have predicted species' local probabilities of occurrence, assumed to be equal to probability of persistence, and targeted areas where probabilities were high. Other approaches to persistence in conservation planning have focused on identifying and targeting areas of presumed and known genetic divergence (Smith et al., 1997; Fjedså and Rahbek, 1998; Moritz and Faith, 1998; Noss et al., 1999; Desmet et al., 2002) - the so-called species factories (Balmford et al., 1998). Noss et al. (1999, 2002) have incorporated environmental gradients and movement corridors in their plans. Our approach to persistence draws on aspects of the approaches mentioned above (species factories, gradients, corridors) and builds on that described in Cowling et al. (1999a) where the spatial components of processes required to maintain and generate biodiversity are identified and targeted. We discuss some of the advantages and shortcomings of this approach below.

The CFR is an area of massive diversity and ongoing diversification, both ecological and geographic (e.g. Rourke, 1972; Goldblatt, 1982; Picker and Samways, 1996; Linder, in press). Consequently, it is essential that a conservation plan for the region incorporates the processes that maintain and will continue to generate this biodiversity (Kruger, 1977; Cowling and Pressey, 2001). We attempted to achieve this by identifying and targeting a wide range of spatial components associated with ecological and evolutionary processes. We also incorporated areas suitable for conserving viable popu- lations of large and medium-sized mammals, thereby ensuring that herbivore- and carnivore-related processes would be maintained over much of the region (Kerley et al., 2003).

Obvious advantages of this approach are that: (i) processes are explicitly targeted and incorporated as stages in the planning processes, not merely considered via generic design criteria; (ii) the entire documented biota is considered; (iii) both ecological and evolutionary processes are accommodated; and (iv) some resilience to climate change impacts is afforded.

There are, however, shortcomings in our approach. Thus, despite a long history of ecological and evolutionary research in the CFR, there is no certainty that all of the process components will, if reserved, fulfil their stated conservation role. Their identification and location were based largely on expert knowledge and the interpretation of a mostly spatially inexplicit literature. Furthermore, we are uncertain whether the configuration and size of the gradients and corridors that we identified will ensure the movement of biota in response to short-term and long-term environmental change. The long-standing debate about the role of corridors in conservation (e.g. Hobbs, 1992; Simberloff et al., 1992; Beier and Noss, 1998) remains unresolved, at least in the sense that there appears to be no design appropriate for all components of a regional biota (Lindenmayer and Nix, 1993; Laurance and Laurance, 1999). Certainly, it is unlikely that the many thousands of CFR plant species that are dispersed short distances by ants (Bond, 1983) will be capable of migrating sufficiently fast to avoid the impacts of anthropogenic climate change (Rutherford et al., 2000; Midgley et al., 2003; see also van Dorp et al., 1997). Also of concern is the location of the upland-lowland and macroclimatic gradients. We recommend that these gradients be interpreted as a framework of axes along which conservation action should be encouraged over as broad a front as possible. This will ensure that that the largest possible pool of genetic material is provided with opportunities to migrate and diversify.

Our plan has explicitly incorporated small and isolated fragments of BHUs (sometimes containing populations of rare proteas and vertebrates) and process components. What are the prospects of biodiversity persistence in these extensively transformed lowland areas? In the short-term, prospects appear reasonably good. As stated in Section 3.2.4, plant and invertebrate diversity, and associated pollination processes, can be maintained in habitat fragments as small as 5 ha provided they are subject to appropriate fire regimes and kept free of invasive plants. While this assessment is derived from empirical data and observations, more rigorous assessments have shown that non-sprouting plants from fire-prone environments in Australia, not dissimilar from those in the CFR, require between 700 
and 1100 ha for the maintenance of viable populations (Burgman et al., 2001). Some Cape plants have been observed since the late 1700 s to have their total populations confined to areas as small as 0.5 ha (Cowling and Eggenberg, 2000; R.M. Cowling, personal observation). Clearly they and, perhaps, some invertebrate species are capable of persisting for a long time in very small areas. However, when occurring in fragmented landscapes, populations of rare and endemic plants and their associated pollinators will probably not escape the impacts of anthropogenic climate change; ensuring persistence will require the restoration of landscape linkages (see Section 5.5) or the establishment of populations in novel ranges (Midgley et al., 2003).

\subsection{Implementation issues}

Despite the importance of implementation in turning plans into reality, few conservation planning studies, at least those published in the primary literature, have considered the issues involved. In this section we discuss implementation of our plan in terms of scheduling, forms of protection, costs, and ongoing review. Implementation issues associated with spatial scale and mainstreaming biodiversity concerns are discussed in Cowling and Pressey (2003) as are current conservation intiatives arising from the CAPE Project.

\subsubsection{Scheduling}

The CAPE Project has an implementation horizon of 20 years (Gelderblom et al., 2003). Biodiversity will continue to be lost during this period especially in high-threat landscapes (Rouget et al., 2003a) where there are few or no options for achieving targets. Given that resources available for conservation will at any time during the implementation period be insufficient to adequately protect all of areas within the plan, a scheduling strategy for conservation action is urgently required.

One such strategy, which is widely advocated, is to focus initially on those areas of high conservation value (measured, for example, by irreplaceability) and high vulnerability to processes that threaten biodiversity (McDowell and Moll, 1992; Faith and Walker, 1996; Pressey et al., 1996; Mittermeier et al., 1998; Groves et al., 2000, Myers et al., 2000; Balmford et al., 2001; Dobson et al., 2001; Pressey and Taffs, 2001). We included in the plan some $9000 \mathrm{~km}^{2}$, or $10.5 \%$ of the planning domain, in the category of maximum irreplaceability and maximum threat. These areas mainly fall within agricultural landscapes where habitats are highly fragmented. However, despite high opportunity costs of implementation (Pence et al., 2003), we strongly recommend that urgent conservation action be undertaken in these areas.

An alternative view of scheduling in relation to threats is to focus initially on large areas of intact habi- tat where vulnerability is low to moderate, and where it is feasible to accommodate a wide range of pattern and processes features, including viable populations of top carnivores (Mittermeier et al., 1998; Noss et al., 1999, 2002; Dinerstein et al., 2000; Faith et al., 2001). This strategy has clear advantages of relatively low opportunity costs (Faith et al., 2001) and low management costs (Frazee et al., 2003); consequently it has been argued that it provides greater biodiversity returns per unit of investment, at least in terms of persistence measures, than a strategy that prioritises action in high-threat landscapes (Faith and Walker, 1996; Ferrier, 2002; Noss et al., 2002).

We see both strategies as complementary rather than as alternatives (see also Mittermeier et al., 1998; Ferrier, 2002). Walking away from vulnerable landscapes where options for target achievement have been exhausted by transformation, will seriously compromise the achievement of a comprehensive conservation goal (Pressey et al., 1996; Balmford et al., 2001; Dobson et al., 2001). However, it makes good sense to implement conservation action in extensive areas of intact habitat where it is possible to achieve a wide array of regional pattern and process targets with relatively little effort and cost. Nonetheless, even for these areas, in order to avoid compromising target achievement, scheduling priority should be established on the basis of vulnerability (Pressey and Taffs, 2001; Noss et al., 2002).

The two strategies outlined earlier raise another important implementation issue: how does one schedule protection among areas that emerge as top priorities for either pattern or process features (Cowling et al., 1999a; Margules and Pressey, 2000)? What is more important: conservation of threatened taxa and endangered habitat, or an interface or gradient that is important for ongoing diversification? Nott and Pimm (1997) argue that processes are not a sufficient target for conservation, but species are. Cowling and Pressey (2001) emphasize the importance of processes for biodiversity persistence, despite the uncertainty of identifying their spatial components (see Section 5.3). The resolution of this issue is a major challenge for conservation planners (Margules and Pressey, 2000).

Conservation value and vulnerability to threats comprise only part of the complex array of constraints and opportunities that determine scheduling in the real world. Of the three main considerations in conservation planning - time, space and human choice-least progress has been made with the last-mentioned. Thus, implementation strategies need also to consider opportunity costs, funding, incentives, willingness to participate, co-operative governance, institutional capacity and so on (Vane-Wright, 1996; Noss et al., 1999; Groves et al., 2000; Theobald et al., 2000; Faith et al., 2001), and the requisite data should be at the same resolution as the biodiversity data (Brooks et al., 2001). Many 
conservation planning studies either ignore these complex socio-economic and political issues (VaneWright, 1996) or defer them to another stage of the planning process (Noss et al., 1999). In reality, the full spectrum of implementation issues should be integrated with all stages of the planning process (Cowling and Pressey, in press). We did not do this in our study and this has compromised our ability to develop an effective scheduling strategy, as we do not have a spatially explicit, region-wide assessment of the full array of implementation opportunities and constraints. These have been more effectively incorporated into the fine-scale study on the Agulhas Plain (Pence et al., 2003) and other fine-scale studies in progress.

\subsubsection{Forms of protection}

Our plan has claimed some $40 \%$ of the remaining intact habitat of the CFR outside existing statutory reserves. Clearly, it will not be feasible for a developing country such as South Africa to pay the massive opportunity costs (Musters et al., 2000) and provide the funds for including all of the targeted land under strict (statutory) reservation (Heydenrych et al., 1999; Frazee et al, 2003; Gelderblom et al., 2003; Pence et al., 2003). There is a wide range of on- and off-reserve mechanisms available to afford protection of conservation-worthy land in the CFR. These include national parks and provincial reserves (statutory reserves), and local authority reserves, Natural Heritage Sites, contractual national parks and conservancies (non-statutory reserves) (see Heydenrych et al., 1999, for details). Recently, some progress has been made with legislation to provide financial incentives for landowners to set aside parts of their properties for conservation (Botha, 2001).

The biggest implementation challenge lies with the high priority landscapes of the agricultural lowlands. It is now widely accepted that the biodiversity-friendly management of agricultural landscapes is essential for nature conservation, especially for features that are endemic to these areas (Gall and Orians, 1992; McIntyre et al., 1992; Jules, 1997). Indeed, some biodiversity features - avifauna in particular - are better represented on farms than within reserves (Little and Crowe, 1998; Morrison and Humphrey, 2001). The cereal-growing areas of the south-western CFR lowlands now harbour the largest populations in the world of South Africa's national bird, the Blue Crane Anthropoides paradiseus (Allan, 1995), a species that was rare in the area in preagricultural times. Some biodiversity-friendly agricultural enterprises do exist in the CFR, for example grazing systems in renosterveld (Donaldson, 2002) and the harvesting of cut flowers in lowland fynbos (Privett et al., 2002). For the most, however, the emphasis will be on the retention of natural habitat fragments in an agricultural matrix.
In an attempt to identify protocols for matching appropriate and feasible protection measures with particular parcels of land on the Agulhas Plain, Pence et al. (2003) showed that a mixed approach involving direct acquisition of $60 \%$ of the targeted area, and off-reserve conservation of the remaining $40 \%$ - using property tax abatement and management assistance (alien plant eradication) as incentives for private landowners - was the most cost-effective way of achieving conservation targets. While most landowners on the CFR lowlands appear willing to collaborate in conservation actions (S.J. Winter, unpublished data), here, as elsewhere, little guidance exists for them to make land-use decisions incorporating principles and knowledge from conservation biology (O'Connell and Noss, 1992). A spirited and effective extension service is required to communicate to landowners that maintaining biodiversity has both indirect and direct economic value (Turpie et al., 2003; see also Pimental et al., 1992; Jules, 1997). Fortunately, such an extension service is in the process of being implemented (see Cowling and Pressey, 2003).

\subsubsection{Costs}

Our plan is ambitious and will be costly to implement, even with off-reserve mechanisms. Frazee et al. (2003) estimated the costs of implementing an earlier plan (Cowling et al., 1999b) that has broadly similar configuration to ours. Of this plan, which encompassed $61 \%$ of the remaining extant area of the CFR, including existing statutory reserves, some 1.5 million ha was allocated to strict reservation and the remaining 1.3 million ha to off-reserve mechanisms. The costing included estimates of acquisition, management and transaction costs, discounted over the 20-year implementation horizon for CAPE. Frazee et al. (2003) estimated an expenditure of $\$ 45.6$ million per year to develop a representative system of conservation areas, and annual costs of \$29.6 million to maintain this system. These figures are small in comparison with the estimate by Turpie et al. (2003) of $\$ 1100$ million per annum for the direct and indirect value derived from the CFR's terrestrial ecosystem goods and services.

Thus, the costs of conserving the CFR are warranted from both a biodiversity and economic perspective. The funds required for implementing the CAPE conservation strategy (Gelderblom et al., 2003; Lochner et al., 2003) will come from both local and global sources. Gelderblom et al. (2003) estimate that the costs of implementing the first 5-year phase (2002-2007) of the CAPE Project are $\$ 16.3$ million per annum, $41 \%$ of which will be derived from local sources and the remainder ( $\$ 9.6$ million per year) from outside sources. International donors, mainly the Global Environment Facility and the Critical Ecosystem Partnership Fund, have made available only $\$ 3.5$ million per annum as a contribution to implementing the first 5-year phase of the CAPE 
project. None of this funding is available for land purchases and much of it will be devoted to activities other than protected area and off-reserve management.

Therefore, the implementation of the bulk of the conservation plan will fall on the shoulders of the three major conservation agencies in the region, all of which are parastatal institutions with financial autonomy. It is estimated that about $20 \%$ of the implementation costs will have to be raised from outside sources; of the remainder, $30 \%$ will be derived from the burgeoning ecotourism on CFR reserves (Turpie et al., 2003), and $50 \%$ through appeals to government to maintain annual costs. The last-mentioned point is problematic since both national and provincial governments continue to cut budgets allocated to conservation agencies, arguing that these should be generated largely from tourism revenue. However, even with innovative agency-private sector partnerships, tourism is unlikely to generate the requisite funds. Furthermore, there are costs of off-reserve conservation-mainly associated with incentive schemes - additional to those that will have to be borne by conservation agencies. For example, Pence et al. (in press) estimate that municipal authorities on the Agulhas Plain, in the south-western lowlands of the CFR, will have to bear a reduction in the rates base of between $\$ 89,000$ and $\$ 179,000$ per annum, depending on the incentive mechanism applied over a 124,000 ha reserve system. It remains to be seen whether local authorities - hard-pressed to provide social serviceswill be willing to bear these costs.

\subsubsection{Ongoing review}

Our conservation plan is not a black box that yields a best solution - it must be constantly updated as new data and insights emerge, targets are adjusted, conservation priorities change (Faith et al., 2001; Noss et al., 2002). In terms of the conservation planning stages outlined by Margules and Pressey (2000), there will be a need to loop back from stage 5 (implementation) to stage 3 (review existing conservation areas), so that progress in implementation can be measured. Unexpected constraints and opportunities encountered during implementation will also require new priority areas to be identified in stage 4 , followed by revised strategies for implementation. The C-Plan decision support system that we used is well suited for this task of ongoing review (Pressey et al., 1995; Pressey, 1999).

But who will manage this review process? One of the earliest outcomes of the CAPE Project was the establishment within the principal conservation agency of a conservation planning unit (see http://cpu.uwc.ac.za) whose task it will be to maintain and update all databases and conduct regular re-runs of the conservation plan in order to provide updates to all users (Gelderblom et al., 2002).

\subsection{Restoration issues}

Extensive areas in our plan will require restoration to achieve conservation targets (Pressey et al., 2003). Specifically, restoration is required to contribute to target shortfalls for 12 BHUs comprising some 408,000 ha. A further 14,500 ha is required to restore parts of the upland-lowland and macroclimatic gradients. Restoration will require both the removal of alien invasive plants and the re-establishment of native vegetation on agricultural landscapes. This will be an expensive business. Pence et al. (2003) estimated a cost of $\$ 46.8$ million to eradicate alien plants from priority areas on the Agulhas Plain, and Frazee et al. (2003) costed alien removal from the areas identified for conservation across the entire CFR at $\$ 105.2$ million (the Agulhas Plain has the worst alien plant problem in the CFR; see Rouget et al., 2003a). Since native vegetation is capable of re-establishing reasonably well after alien plant removal under most circumstances, revegetation will be unnecessary (Holmes and Richardson, 1999). Nothing is known about the process and costs restoration of agricultural lands in the CFR. Given the scale of modification, and the possibility of irreversible changes in soil properties, this is likely to be both difficult and expensive (Hobbs, 1993).

While great strides have been made with removing alien vegetation within the CFR over many decades, but especially under the Working for Water Programme (Gelderblom et al., 2003), clearing priorities have been largely focused in mountain catchments in order to protect water supplies (van Wilgen et al., 1996). Priority areas on the lowlands have been largely ignored. Exceptions include the Agulhas Plain (Privett et al., 2002) and parts of the southeastern lowlands near Port Elizabeth.

An omission of the CAPE Project is a detailed analysis of restoration priorities, requirements and costs. Such an analysis, which is urgently required, will require co-operation among agencies responsible for restoration in order to align strategies so that meaningful conservation targets can be achieved in addition to other objectives such as catchment management and job creation.

\section{Conclusion}

We have attempted to incorporate into the plan the two principal objectives for a system of conservation areas: representativeness (sample the full variety of biodiversity) and persistence (promote the long-term survival of biodiversity by maintaining natural processes and viable populations and by excluding threats) (Margules and Pressey, 2000). The plan is underpinned by a great deal of uncertainty, especially with regard to the 
effectiveness of surrogates for biodiversity of pattern and process. We have probably excluded from our system much biodiversity that is unmapped or unknown (Pressey et al., 2003). The system should be viewed a set of hypotheses about the maintenance of biodiversity and ongoing diversification in the CFR. It should be subject to continual evaluation and refinement as more data and expert knowledge become available.

Despite being considered a conservation bargain (Frazee et al., 2003), there will probably be insufficient funds to implement the plan in its entirety. Biodiversity will continue to be lost during the implementation phase and thereafter, but hopefully at a slower rate than in other hotspots (Pimm et al., 1995). Off-reserve implementation mechanisms will probably prevail, and there will be an emphasis on the utility rather than the intrinsic value of biodiversity. There is no guarantee that community-based, off-reserve actions will ensure that biodiversity targets are achieved and maintained (Redford and Richter, 1999).

The plan provides spatially explicit guidelines for achieving the CAPE goal. Much will happen of the next 20 years that will influence its implementation. A process has been initiated that is ambitious and challenging. Safeguarding the world's embattled biodiversity demands nothing less.

\section{Acknowledgements}

Aspects of this study were funded by the Global Environment Facility through World Wide FundSouth Africa (WWF-SA), the University of Port Elizabeth, New South Wales National Parks and Wildlife Service and Conservation International's Southern African Hotspots Program. The paper benefited greatly from review by Neil Burgess and Tony Rebelo, and from discussions with Andre Boshoff, Mark Botha, Philip Desmet, Simon Ferrier, Graham Kerley, Peter Linder, Kristal Maze, Dave Richardson and Brian van Wilgen.

\section{References}

Allan, D.G., 1995. Habitat selection by Blue Cranes in the western Cape Province and the Karoo. South African Journal of Wildlife Research 25, 90-97.

Baker, W.L., 1989. Landscape ecology and nature reserve design in the Boundary Waters Canoe Area, Minnesota. Ecology 70, 23-35.

Balmford, A., Mace, G, Ginsberg, J.R., 1998. The challenges to conservation in a changing world: putting processes on the map. In: Mace, G., Balmford, A., Ginsberg, J.R. (Eds.), Conservation in a Changing World. Cambridge University Press, Cambridge, pp. 1-28.

Balmford, A., Moore, J.L., Brooks, T., Burgess, N., Hansen, L.A., Williams, P., Rahbek, C., 2001. Conservation conflicts across Africa. Science 29, 2616-2619.
Beier, P., Noss, R.F., 1998. Do habitat corridors provide connectivity? Conservation Biology 12, 1241-1252.

Bond, W.J., 1983. Seed dispersal by ants in shrublands of the Cape Province and its evolutionary implications. South African Journal of Science 79, 231-233.

Bond, W.J., Midgley, J., Vlok, J., 1988. When is an island not an island? Insular effects and their causes in fynbos shrublands. Oecologia 77, 515-521.

Bond, W.J., Vlok, J., Viviers, M., 1984. Variations in seedling recruitment of Cape Proteaceae after fire. Journal of Ecology 72, 209-221.

Bond, W.J., van Wilgen, B.W., 1996. Fire and Plants. Chapman \& Hall, London.

Boshoff, A., Cowling, R., Kerley, G., 2000. The Baviaanskloof Conservation Area: A Conservation and Tourism Development Priority. Terrestrial Ecology Research Unit Report 27, University of Port Elizabeth, South Africa.

Boshoff, A.F., Kerley, G.I.H., 2001. Potential distributions of the medium- to large-sized mammals in the Cape Floristic Region, based on historical accounts and habitat requirements. African Zoology 36, 245-273.

Boshoff, A.F., Kerley, G.I.H., Cowling, R.M., 2001. A pragmatic approach to estimating the distributions and spatial requirements of the medium- to large-sized mammals in the Cape Floristic Region. Diversity and Distributions 7, 29-44.

Boshoff, A.F., Kerley, G.I.H., Cowling, R.M., 2002. Estimated spatial requirements of the medium- to large-sized mammals, according to broad habitat units, in the Cape Floristic Region. African Journal of Range and Forage Science 19, 29-44.

Botha, M.A., 2001. Conservation Options for Farmers and Private Landowners. The Botanical Society of South Africa, Cape Conservation Unit, Report 01/2001.

Branch, W.R., 1988. South African Red Data Book-Reptiles and Amphibians. South African National Programmes Report No 151. CSIR, Pretoria.

Brooks, T., Balmford, A., Burgess, N., Fjeldså, J., Hansen, L.A., Moore, J., Rahbek, C., Williams, P., 2001. Towards a blueprint for conservation in Africa. BioScience 51, 613-624.

Burgman, M.A., Possingham, H.P., Jasmyn, A., Lynch, J., Keith, D.A., McCarthy, M.A., Hopper, S.D., Drury, W.D., Passioura, J.A., Devries, R.J., 2001. A method for setting the size of plant conservation area. Conservation Biology 15, 603-616.

Carroll, C., Noss, R.F., Paquet, P.C., 2001. Carnivores as focal species for conservation planning in the Rocky Mountain region. Ecological Applications 11, 961-980.

Carruthers, V., 2001. Frogs and Frogging in Southern Africa. Struik Publishers, Cape Town.

Caughley, G., 1994. Directions in conservation biology. Journal of Animal Ecology 63, 215-244.

Colville, J., Picker, M.D., Cowling, R.M., 2002. Species turnover of monkey beetles (Scarabaenidae: Hoplini) along environmental and disturbance gradients in the Namaqualand region of the Succulent Karoo, South Africa. Biodiversity and Conservation 11, 243-264.

Cowling, R.M., Bond, W.J., 1991. How small can reserves be? An empirical approach in Cape Fynbos, South Africa. Biological Conservation 58, 243-256.

Cowling, R.M., Eggenberg, S., 2000. Accommodating problems of rarity definition and phylogeny in assessing common-rare differences in reproductive effort: opportunities provided by the Cape Flora. South African Journal of Science 96, 381-384.

Cowling, R.M., Heijnis, C.E., 2001. The identification of broad habitat units as biodiversity entities for a systematic conservation planning in the Cape Floristic Region. South African Journal of Botany $67,15-38$.

Cowling, R.M., Hilton-Taylor, C., 1994. Plant diversity and endemism in southern Africa: an overview. In: Huntley, B.J. (Ed.), Botanical Diversity in Southern Africa. National Botanical Institute, Kirstenbosch, pp. 31-52. 
Cowling, R.M., Holmes, P.M., 1992. Flora and vegetation. In: Cowling, R.M. (Ed.), The Ecology Of Fynbos: Nutrients, Fire and Diversity. Oxford University Press, Cape Town, pp. 23-61.

Cowling, R.M., Lombard, A.T., 2002. Heterogeneity, speciation/ extinction history and climate: explaining regional plant diversity patterns in the Cape Floristic Region. Diversity and Distributions 8, 163-179.

Cowling, R.M., Pressey, R.L., 2001. Rapid plant diversification: planning for an evolutionary future. Proceedings of the National Academy of Sciences of the United States 98, 5452-5457.

Cowling, R.M., Pressey, R.L., 2003. Introduction to systematic conservation planning in the Cape Floristic Region. Biological Conservation 112, 1-13.

Cowling, R.M., Pressey, R.L., Lombard, A.T., Desmet, P.G., Ellis, A.G., 1999a. From representation to persistence: requirements for a sustainable system of conservation areas in the species-rich mediterranean-climate desert of southern Africa. Diversity and Distributions 5, 51-71.

Cowling, R.M., Pressey, R.L., Lombard, A.T., Heijnis, C.E., Richardson, D.M., Cole, N., 1999b. Framework for a Conservation Plan for the Cape Floristic Region. IPC Report 9902. Institute for Plant Conservation, University of Cape Town.

Davis, S.D., Heywood, V.H., Hamilton, A.C. (Eds.), 1994. Centres of Plant Diversity. A Guide and Strategy for their Conservation. Vol. 1. Europe, Africa, South West Asia and The Middle East. WWF and IUCN, IUCN Publications Unit, Cambridge.

Dent, M.C., Lynch, S.D., Tarboton, H., 1990. Detailed delimitation of rainfall regions in southern Africa. Water SA 16, 1-4.

Desmet, P.G., Cowling, R.M., Ellis, A.G., Pressey, R.L., 2002. Integrating biosystematic data into conservation planning: perspectives from southern Africa's Succulent Karoo. Systematic Biology 51, $317-330$.

Dimmick, W.W., Ghedotti, M.J., Grose, M.J., Maglia, A.M., Meinhardt, D.J., Pennock, D.S., 1999. The importance of systematic biology in defining units of conservation. Conservation Biology 13, 653-660.

Dinerstein, E., Powell, G., Olson, D., Wikramanayake, E., Abell, R., Loucks, C., Underwood, E., Allnutt, T., Wttengel, W., Ricketts, T., Strand, H., O'Connor, S., Burgess, N., 2000. A Workbook for Conducting Biological Assessments and Developing Biodiversity Visions for Ecoregion-Based Conservation. Part 1: Terrestrial Ecoregions. Conservation Science Program, WWF-USA, Washington, DC.

Dobson, A.P., Rodríguez, J.P., Roberts, M.W., 2001. Synoptic tinkering: integrating strategies for large-scale conservation. Ecological Applications 11, 1019-1026.

Donaldson, J.S., 2002. Biodiversity and conservation farming in the agricultural sector. In: Pierce, S.M., Cowling, R.M., Sandwith, T., MacKinnon, K. (Eds.), Mainstreaming Biodiversity in Development. Case Studies from South Africa. World Bank, Washington, DC, pp. 43-56.

Donaldson, J., Nänni, I., Zachariades, C., Kemper, J., 2002. Effects of habitat fragmentation on pollinator diversity and plant reproductive success in renosterveld shrublands of South Africa. Conservation Biology 16, 1267-1276.

Enrödy-Younga, S., 1988. Evidence for the low-altitiude origin of the Cape Mountain Biome derived from the systematic revision of the genus Colophon (Gray (Coleoptera, Lucanidae). Annals of the South African Museum 96, 359-424.

Faith, D.P., Margules, C.R., Walker, P.A., 2001. A biodiversity conservation plan for Papua New Guinea based on biodiversity tradeoffs analysis. Pacific Conservation Biology 6, 304-324.

Faith, D.P., Walker, P.A., 1996. Integrating conservation and development: incorporating vulnerability into biodiversity-assessment of areas. Biodiversity and Conservation 5, 417-429.

Ferrier, S., 2002. Mapping spatial pattern in biodiversity for regional conservation planning: where to from here? Systematic Biology 51, $331-363$
Ferrier, S., Pressey, R.L., Barrett, T.W., 2000. A new predictor of the irreplaceability of areas for achieving a conservation goal, its application to real-world planning, and research agenda for further refinement. Biological Conservation 93, 303-326.

Fjedså, J., Rahbek, C., 1998. Endemism and species turnover with elevation in montane avifaunas in the neotropics: implications for conservation. In: Mace, G., Balmford, A., Ginsberg, J.R. (Eds.), Conservation in a Changing World. Cambridge University Press, Cambridge, pp. 161-180.

Foster, D.R., 2000. From bobolinks to bears: interjecting geographical history into ecological studies, environmental interpretation, and conservation planning. Journal of Biogeography 27, 27-30.

Frazee, S., Cowling, R.M., Pressey, R.L., Turpie, J.K., Lindenberg, N., 2003. Estimating the costs of conserving a biodiversity hotspot: a case study of the Cape Floristic Region, South Africa. Biological Conservation 112, 275-290.

Gall, G.A.E., Orians, G.H., 1992. Agriculture and biological conservation. Agriculture, Ecosystems and Environment 42, 1-8.

Gelderblom, C.M., Kruger, D., Cedras, L., Sandwith, T., Audouin, M., 2002. Incorporating conservation priorities into planning guidelines for the Western Cape. In: Pierce, S.M., Cowling, R.M., Sandwith, T., MacKinnon, K. (Eds.), Mainstreaming Biodiversity in Development. Case Studies from South Africa. World Bank, Washington DC, pp. 129-142.

Gelderblom, C.M., Van Wilgen, B.W., Nel, J., Sandwith, T., Botha, M., Hauck, M., 2003. Turning strategy into action: implementing a conservation action plan in the Cape Floristic Region. Biological Conservation 112, 291-297.

Goldblatt, P., 1982. Systematics of Freesia Klatt (Iridaceae). Journal of South African Botany 48, 39-91.

Goldblatt, P., Manning, J.C., 1999. The long-proboscid fly pollination system in Gladiolus (Iridaceae). Annals of the Missouri Botanical Garden 86, 758-774.

Goldblatt, P., Manning, J., 2002. Plant diversity of the Cape Region of South Africa. Annals of the Missouri Botanical Garden 89, 281-302.

Groves, C.R., Jensen, D.B., Valutis, L.L., Redford, K.H., Shaffer, M.L., Scott, J.M., Baumgartner, J.V., Higgins, J.V., Beck, M.W., Anderson, M.G., 2002. Planning for biodiversity conservation: putting conservation science into practice. BioScience 52, 499-512.

Groves, C., Valutis, L., Vosick, D., Neely, B., Wheaton, K., Trouval, J., Runnels, B., 2000. Designing a Geography of Hope. A Practioner's Guide for Ecoregional Conservation Planning. The Nature Conservancy, Washington, DC.

Hammond, P.M., 1992. Species inventory. In: Groombridge, B. (Ed.), Global Biodiversity. Status of the Earth's Living Resources. Chapman \& Hall, London, pp. 17-39.

Hanski, I., Ovaskainen, O., 2000. The metapopulation capacity of a fragmented landscape. Nature 404, 755-758.

Heydenrych, B.J., Cowling, R.M., Lombard, A.T., 1999. Strategic conservation interventions in a region of high biodiversity and high vulnerability: a case study from the Agulhas Plain at the southern tip of Africa. Oryx 33, 256-269.

Hobbs, R.J., 1992. The role of corridors in conservation-solution or bandwagon. Trends in Ecology and Evolution 7, 389-392.

Hobbs, R.J., 1993. Can revegetation assist in the conservation of biodiversity in agricultural areas? Pacific Conservation Biology 1, 2938.

Holmes, P.M., Richardson, D.M., 1999. Protocols for restoration based on recruitment dynamics, community structure, and ecosystem function: perspectives from South African fynbos. Restoration Ecology 7, 215-229.

Howard, P.C., Davenport, T.R.B., Kigenyi, F.W., Viskanic, P., Baltzer, M.C., Dickinson, C.J., Lwanga, J., Matthews, R.A., Mupada, E., 2000. Protected area planning in the tropics: Uganda's national system of forest nature reserves. Conservation Biology 14, 858-875.

Impson, N.D., Bills, I.R., Cambray, J.A., Le Roux, A., 1999. The Primary Freshwater Fishes of the Cape Floristic Region: 
Conservation Needs for a Unique and Highly Threatened Fauna. Western Cape Nature Conservation Board, Jonkershoek, South Africa.

Johnson, S.D., 1995. Pollination, adaptation and speciation models in the Cape flora of South Africa. Taxon 45, 59-66.

Jules, E.S., 1997. Dangers in dividing conservation biology and agroecology. Conservation Biology 11, 1272-1273.

Kemper, J., Cowling, R.M., Richardson, D.M., 1999. Fragmentation of South African renosterveld shrublands: effects on plant community structure and conservation implications. Biological Conservation 90, 103-111.

Kemper, J., Cowling, R.M., Richardson, D.M., Forsyth, G.C., McKelly, D.H., 2000. Landscape patterns and their correlates in a fragmented ecosystem: South Coast Renosterveld, South Africa. Austral Ecology 25, 179-186.

Kerley, G.I.H., Pressey, R.L., Cowling, R.M., Boshoff, A.F., SimsCastley, R., 2003. Options for the conservation of large and medium-sized mammals in the Cape Floristic Region. Biological Conservation 112, 169-190.

Kirkpatrick, J.B., Gilfedder, L., 1995. Maintaining integrity compared with maintaining rare and threatened taxa in remnant bushland in subhumid Tasmania. Biological Conservation 74, 1-8.

Kruger, F.J., 1977. Ecological reserves in the Cape fynbos: toward a strategy for conservation. South African Journal of Science 73, 8185.

Lacy, R.C., 1997. Importance of genetic variation to the viability of mammalian populations. Journal of Mammalogy 78, 320-335.

Laurance, S.G., Laurance, W.F., 1999. Tropical wildlife corridors: use of linear rainforest remnants by arboreal mammals. Biological Conservation 91, 231-239.

Lechmere-Oertel, R., Cowling, R.M., 2001. Abiotic determinants of the fynbos/succulent karoo boundary, South Africa. Journal of Vegetation Science 12, 75-80.

Lindenmayer, D.B., Nix, H.A., 1993. Ecological principles for the design of wildlife corridors. Conservation Biology 7, 627-630.

Linder, H.P., The Cape flora. Biological Review (in press).

Little, R.M., Crowe, T.M., 1998. Habitat fragmentation limits the distribution of Cape francolin Francolinus capensis, on deciduous fruit farms in South Africa. African Journal of Ecology $36,140-147$.

Lloyd, J.W., van der Berg, E.C., van Wyk, E., 1999. The mapping of threats to the Cape Floristic Region with the aid of remote sensing and geographic information systems. Institute for Soil and Climate: Agricultural Research Council, Pretoria.

Lochner, P., Weaver, A., Gelderblom, C., Paert, R., Sandwith, T., Fowkes, S., 2003. Aligning the diverse: the development of a biodiversity conservation strategy for the Cape Floristic Region. Biological Conservation 112, 29-43.

Lombard, A.T., Pressey, R.L., Cowling, R.M., Rebelo, A.G., 2003. Effectiveness of land classes as surrogates for species. Biological Conservation 112, 45-62.

Margules, C.R., Pressey, R.L., 2000. Systematic conservation planning. Nature 405, 243-253.

Margules, C.R., Stein, J.L., 1989. Patterns in the distributions of species and the selection of nature reserves: an example from Eucalyptus forests in south-eastern New South Wales. Biological Conservation 50, 219-238.

McDowell, C., Moll, E., 1992. The influence of agriculture on the decline of West Coast Renosterveld, south-western Cape, South Africa. Journal of Environmental Management 35, 173-192.

McIntyre, S., Barret, G.W., Kitching, R.L., Recher, H.F., 1992. Species triage - seeing beyond wounded rhinos. Conservation Biology 6, 605-606.

Midgley, G., Hannah, L., Millar, D., Thuiller, W., Booth, A., 2003. Developing regional and species-level assessments of climate change impacts on biodiversity in the Cape Floristic Region. Biological Conservation 112, 87-97.
Mills, M.G.L., 1997. Wild dog conservation in South Africa-perspectives, problems, plans. In: Mills, G.G.L., Girsham, J., Ellis, S. (Eds.), African Wild Dog (Lycaon pictus). Population and Habitat Viability Assessment Briefing Book. Section 4. IUCN/SSC Conservation Breeding Specialist Group, Apple Valley, MN.

Mittermeier, R.A., Myers, N., Thorsen, J.B., da Fonseca, G.A.B., Olivieri, S., 1998. Biodiversity hotspots and major tropical wilderness areas: approaches to setting conservation priorities. Conservation Biology 12, 516-520.

Moritz, C., 2002. Strategies to protect biological diversity and the evolutionary processes that sustain it. Systematic Biology 51, 238-254.

Moritz, C., Faith, D., 1998. Comparative phylogeography and the identification of genetically divergent areas for conservation. Molecular Ecology 7, 419-429.

Morrison, J.L., Humphrey, S.R., 2001. Conservation value of private lands for Crested Caracaras in Florida. Conservation Biology 15, 675-684.

Musters, C.J.M., de Graaf, H.J., ter Keurs, W.J., 2000. Can protected areas be expanded in Africa? Science 287, 1759-1760.

Myers, N., Mittermeier, R.A., Mittermeier, C.G., da Fonseca, G.A.B., Kent, J., 2000. Biodiversity hotspots for conservation priorities. Nature 403, 853-858.

Noss, R.F., Carroll, C., Vance-Borland, K., Wuerthner, G., 2002. A multicriteria assessment of the irreplaceability and vulnerability of sites in the Greater Yellowstone Ecosystem. Conservation Biology 16, 895-908.

Noss, R.F., Cooperrider, A., 1994. Saving Nature's Legacy: Protecting and Restoring Biodiversity. Defenders of Wildlife and Island Press, Washington DC.

Noss, R.F., Strittholt, J.R., Vance-Borland, K., Carroll, C., Frost, P., 1999. A conservation plan for the Klamath-Siskiyuo Ecoregion. Natural Areas Journal 19, 392-411.

Nott, M.P., Pimm, S.L., 1997. The evaluation of biodiversity as a target for conservation. In: Pickett, S.T.A. (Ed.), The Ecological Basis of Conservation: Heterogeneity, Ecosystems, and Biodiveristy. Chapman \& Hall, New York, pp. 125-135.

O'Connell, M.A., Noss, R.F., 1992. Private land management for biodiversity conservation. Environmental Management 16, 435-450.

Olson, D.M., Dinerstein, E., 1998. The global 200: a representation approach to conserving the earth's most biologically valuable ecoregions. Conservation Biology 12, 502-515.

Pence, G., Botha, M., Turpie, J.K., 2003. Evaluating combinations of on-and off-reserve conservation strategies for the Agulhas Plain, South Africa: a financial perspective. Biological Conservation 112, 253-273.

Picker, M.D., Samways, M.J., 1996. Faunal diversity and endemicity of the Cape Peninsula, South Africa - a first assessment. Biodiversity and Conservation 5, 591-606.

Pimental, D., Stachow, U., Takacs, D.A., Brubaker, H.W., Dumas, A.R., Meaney, J.J., O’Neil, A.S., Onsi, D.E., Corzilius, D.B., 1992. Conserving biological diversity in agricultural/forestry systems. BioScience 42, 354-362.

Pimm, S.L., Russell, G.J., Gittleman, J.L., Brooks, T.M., 1995. The future of biodiversity. Science 269, 347-350.

Poiani, K.A., Richter, B.D., Anderson, M.G., Richter, H.E., 2000. Biodiversity conservation at multiple scales: functional sites, landscapes, and networks. BioScience 50, 133-146.

Possingham, H.P., Ball, I.R., Andelman, S., 2000. Mathematical methods for identifying representative reserve networks. In: Ferson, S., Burman, M. (Eds.), Quantitative Methods for Conservation Biology. Springer-Verlag, New York, pp. 291-306.

Pressey, R.L., 1999. Applications of irreplaceability analysis to planning and management problems. Parks 9, 42-51.

Pressey, R.L., Cowling, R.M., 2001. Reserve selection algorithms and the real world. Conservation Biology 15, 275-277.

Pressey, R.L., Cowling, R.M., Rouget, M., 2003. Formulation of conservation targets for biodiversity pattern and process in the Cape 
Floristic Region, South Africa. Biological Conservation 112, 99127.

Pressey, R.L.S., Ferrier, T.C.Hager, C.A. Woods, S.L.Tully, Weinman, K.M., 1996. How well protected are the forests of north-eastern New South Wales? - analyses of forest environments in relation to tenure, formal protection measures and vulnerability to clearing. Forest Ecology and Management 85, 311-333.

Pressey, R.L., Ferrier, S., Hutchinson, C.D., Siverstein, D.P., Manion, G., 1995. Planning for negotiation: using an interactive geographic information system to explore alternative protected area networks. In: Saunders, D.A., Craig, J.L., Mattiske, E.M. (Eds.), Nature Conservation 4: The Role of Networks. Surrey Beatty \& Sons, Sydney, pp. 23-33.

Pressey, R.L., Humphries, C.J., Margules, C.R., Vane-Wright, R.I., Williams, P.H., 1993. Beyond opportunism: key principles for systematic reserve selection. Trends in Ecology and Evolution 8, 124 128.

Pressey, R.L., Logan, V.S., 1998. Size of selection units for future reserves and its influence on actual vs targeted representation of features: a case study in western New South Wales. Biological Conservation 85, 305-319.

Pressey, R.L., Taffs, K.H., 2001. Scheduling conservation action in production landscapes: priority areas in western New South Wales defined by irreplaceability and vulnerability to vegetation loss. Biological Conservation 100, 355-376.

Privett, S.D.J., Heydenrych, B.J., Cowling, R.M., 2002. Putting biodiversity to business on the Agulhas Plain. In: Pierce, S.M., Cowling, R.M., Sandwith, T., MacKinnon, K. (Eds.), Mainstreaming Biodiversity in Development. Case Studies from South Africa. World Bank, Washington DC, pp. 101-116.

Rebelo, A.G., 1992. Preservation of biotic diversity. In: Cowling, R.M. (Ed.), The Ecology of Fynbos. Nutrients, Fire and Diversity. Oxford University Press, Cape Town, pp. 309-344.

Rebelo, A.G., 1997. Conservation. In: Cowling, R.M., Richardson, D.M., Pierce, S.M. (Eds.), Vegetation of Southern Africa. Cambridge University Press, Cambridge, pp. 571-590.

Rebelo, A.G., 2001. Proteas. A Field Guide to the Proteas of Southern Africa. Fernwood Press, Cape Town.

Rebelo, A.G., Siegfried, W.R., 1990. Protection of fynbos vegetation: ideal and real-world options. Biological Conservation 54, 17-34.

Rebelo, A.G., Siegfried, W.R., 1992. Where should nature reserves be located in the Cape Floristic region, South Africa? Models for the spatial configuration of a reserve network aimed at maximizing the protection of floral diversity. Conservation Biology 6, 243-252.

Redak, R.A., 2000. Arthropods and multispecies habitat conservation plans: are we missing something? Environmental Management 26 (Supplement 1), S97-S107.

Redford, K.H., Richter, B.D., 1999. Conservation of biodiversity in a world of use. Conservation Biology 13, 1246-1256.

Reed, J.M., Mills, L.S., Dunning, J.B., Menges, E.S., McKelvey, K.S., Frye, R., Beissinger, S.R., Anstett, M.C., Miller, P., 2002. Emerging issues in population viability analysis. Conservation Biology 16, 719.

Richards, M.B., Cowling, R.M., Stock, W.D., 1997. Soil factors and competition as determinants of the distribution of six fynbos Proteaceae species. Oikos 79, 394-406.

Richardson, D.M., Macdonald, I.A.W., Holmes, P.M., Cowling, R.M., 1992. Plant and animal invasions. In: Cowling, R.M. (Ed.), The Ecology of Fynbos. Nutrients, Fire and Diversity. Oxford University Press, Cape Town, pp. 271-308.

Rodrigues, A.S.L., Cerdeira, J.O., Gaston, K.J., 2000. Flexibilty, efficiency, and accountability: adapting reserve selection algorithms to more complex conservation problems. Ecography 23, 565-574.

Rouget, M., Richardson, D.M., Cowling, R.M., Lloyd, J.W., Lombard, A.T., 2003a. Current patterns of habitat transformation and future threats to biodiversity in terrestrial ecosystems of the Cape Floristic Region, South Africa. Biological Conservation 112, 63-85.
Rouget, M., Richardson, D.M., Cowling, R.M., 2003b. The current configuration of protected areas in the Cape Floristic Region, South Africa-reservation bias and representation of biodiversity patterns and processes. Biological Conservation 112, 129-145.

Rouget, M., Cowling, R.M., Pressey, R.L., Richardson, D.M., Identifying the spatial components of ecological and evolutionary processes for regional conservation planning in the Cape Floristic Region. Diversity and Distributions (in press).

Rourke, J.P., 1972. Taxonomic studies on Leucospermum R.Br. Journal of South African Botany, Supplementary 8, 1-194.

Rutherford, M.C., Powrie, L.W., Schulze, R.E., 2000. Climate change in conservation areas of South Africa and its potential impact on floristic composition: a first assessment. Diversity and Distributions $5,253-262$.

Schwartz, M.W., 1999. Choosing the appropriate scale of reserves for conservation. Annual Review of Ecology and Systematics 30, 83108.

Simberloff, D., Farr, J.A., Cox, J., Mehlman, D.W., 1992. Movement corridors - conservation bargains or poor investments. Conservation Biology 6, 493-504.

Skelton, P., 1993. A Complete Guide to the Freshwater Fishes of Southern Africa. Southern Book Publishers, Halfway House, South Africa.

Skelton, P.H., Cambray, J.A., Lombard, A.T., Benn, G.A., 1995. Patterns of distribution and conservation status of freshwater fishes in South Africa. South African Journal of Zoology 30, 71-81.

Smith, T.B., Bruford, M.W., Wayne, R.K., 1993. The preservation of process: the missing element of conservation programs. Biodiversity Letters 1, 164-167.

Smith, T.B., Wayne, R.K., Girman, D.J., Bruford, M.W., 1997. A role for ecotones in generating rainforest biodiversity. Science 276, 1855 1857.

Smithers, R.H.N., 1986. South African Red Data Book-Terrestrial Mammals. South African National Scientific Programmes Report 125. CSIR, Pretoria.

Soulé, M.E., Sanjayan, M.A., 1998. Conservation targets: do they help? Science 279, 2060-2061.

Soulé, M.E., Terborgh, J., 1999. Continental Conservation: Scientific Foundations of Regional Reserve Networks. Island Press, Washington DC.

Steiner, K.E., 1998. Beetle pollination of peacock moraeas (Iridaceae) in South Africa. Plant Systematics and Evolution 209, 47-65.

Stattersfield, A.J., Crosby, M.J., Long, A.J., Wedge, D.C., 1998. Endemic Bird Areas of the World. BirdLife Conservation Series 7. BirdLife International, Cambridge.

Stuckenberg, B.R., 1962. The distribution of the montane palaeogenic element in the South African invertebrate fauna. Annals of the Cape Provincial Museum 11, 119-158.

Terborgh, J., Estes, J.A., Paquet, P., Ralls, K., Boyd-Heger, D., Miller, B.J., Noss, R.F., 1999. The role of top carnivores in regulating terrestrial ecosystems. In: Soulé, M.E., Terborgh, J. (Eds.), Continental Conservation. Scientific Foundation of Regional Reserve Networks. Island Press, Washington DC, pp. 65-98.

Terborgh, J., Soulé, M.E., 1999. Why we need mega-reserves and how to design them. In: Soulé, M.E., Terborgh, J. (Eds.), Continental Conservation. Scientific Foundation of Regional Reserve Networks. Island Press, Washington DC, pp. 199-210.

Theobald, D.M., Hobbs, N.T., Bearly, T., Zack, J.A., Shenk, T., Riebsame, W.E., 2000. Incorporating biological information into local land-use decision making: designing a system for conservation planning. Landscape Ecology 15, 35-45.

Turpie, J.K., Heydenrych, B.J., Lamberth, S.J., 2003. Economic value of terrestrial and marine biodiversity in the Cape Floristic Region: implications for defining effective and socially optimal conservation strategies. Biological Conservation 112, 233-251.

Underhill, L.G., 1994. Optimal and suboptimal reserve selection algorithms. Biological Conservation 70, 85-87. 
van Dorp, D., Schippers, P., van Groenendael, J.M., 1997. Migration rates of grassland plants along corridors in fragmented landscapes assessed with a cellular automation model. Landscape Ecology 12, $39-50$.

van Wilgen, B.W., Cowling, R.M., Burgers, C.J., 1996. Valuation of ecosystem services. BioScience 46, 184-189.

Vane-Wright, R.I., 1996. Identifying priorities for the conservation of biodiversity: systematic biological criteria within a socio-political framework. In: Gaston, K.J. (Ed.), Biodiversity. A Biology of Numbers and Difference. Blackwell Science, Oxford, pp. 309-344.

Williams, P.H., Araújo, M.B., 2000. Using probability of persistence to identify important areas for biodiversity conservation. Proceedings of the Royal Society London B 267, 1959-1966.
Woodroffe, R., Ginsberg, J., 1997. Country-by-country action plans for wild dog conservation. In: Woodroffe, R., Ginsberg, J., MacDonald, D.W. (Eds.), The African Wild Dog-Status Survey and Conservation Action Plan. IUCN, Gland, pp. 118-123.

Wright, M.G., Samways, M.J., 1999. Plant characteristics determine insect borer assemblages on Protea species in the Cape Fynbos, and importance for conservation management. Biodiversity and Conservation 8, 1089-1100.

Younge, A., Ashwell, M., 2000. Cape Action Plan for the Environment: A Biodiversity Strategy for the Cape Floral Kingdom. World Wildlife Fund-South Africa, Stellenbosch.

Younge, A., Fowkes, S., 2003. The Cape Action Plan for the Environment: overview of an ecoregional planning process. Biological Conservation 112, 15-28. 